\title{
Acinetobactin Isomerization Enables Adaptive Iron Acquisition in Acinetobacter baumannii through pH-Triggered Siderophore Swapping
}

\author{
Supporting Information
}

\author{
Justin A. Shapiro and Timothy A. Wencewicz* \\ Department of Chemistry, Washington University in St. Louis, One Brookings Drive, St. Louis, \\ MO, 63130, USA
}

\section{Table of Contents}

I. Biosynthesis and Transport of Acinetobactin......................Scheme S1; S2-S3.

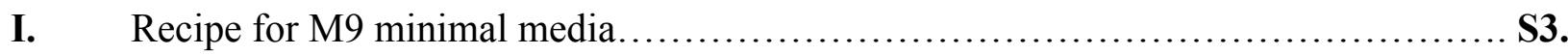

II. Procedures for Compound Synthesis ............................ Scheme S2; S4-S8.

III. Kinetic UV-Vis Spectra of Acinetobactin Isomerization ............... Figure S1; S9-S10.

IV. Kinetic LC-MS Chromatograms of Acinetobactin Isomerization ........... Figure S2-S3; S10-S11.

V. Kinetic ${ }^{1}$ H-NMR Spectra of Acinetobactin Isomerization...... Figures S4-S12; Table S1; S11-S16.

VI. CD Spectra of Acinetobactin Samples ............................ Figure S13; S17.

VII. High-Res MS-MS of Pure Compounds ...... Figures S14-S19; Schemes S3-S6; S18-S22.

VIII. Titrations of Apo-Siderophores with Tris(acetylacetonato) Iron(III)........Figure S20; S23

IX. NMR Data for Pure Compounds ............ Figures S21-S34; Tables S2-S3; S24-S39.

X. A. baumannii Growth Curves ............................................ Figures S35-36; S40-41.

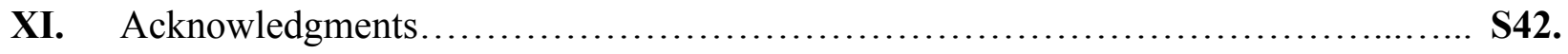

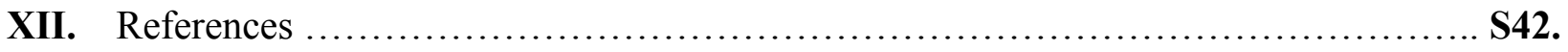




\section{Biosynthesis and Transport of Acinetobactin}

A.

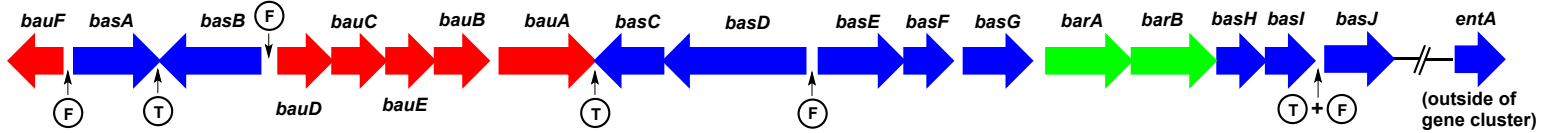

B.

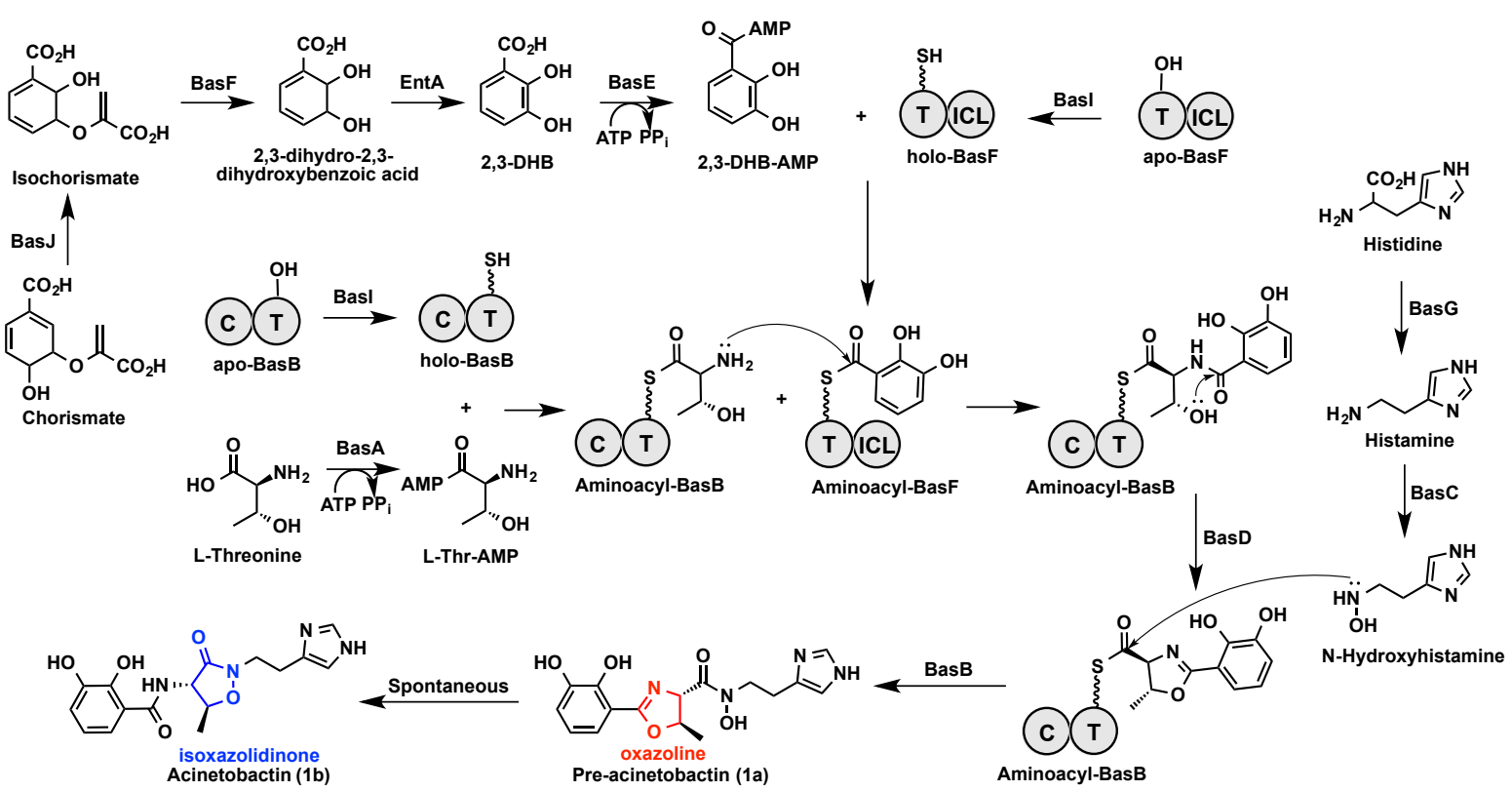

C.

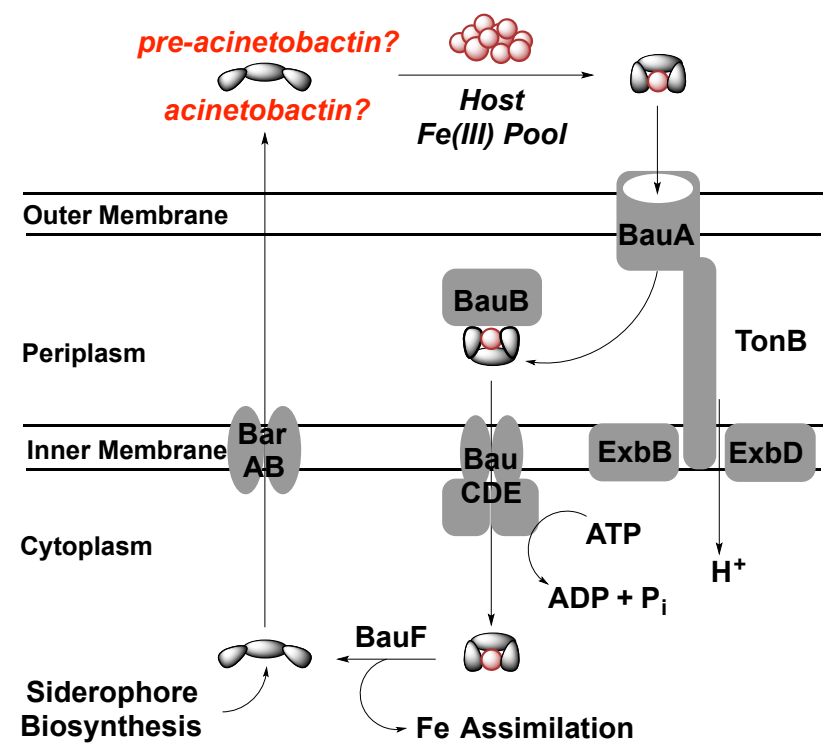

D.

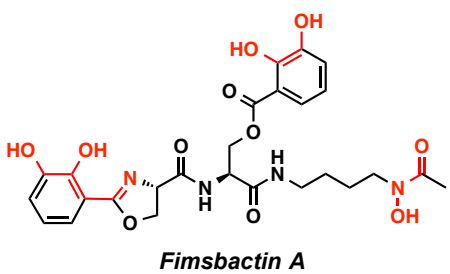

Fimsbactin A

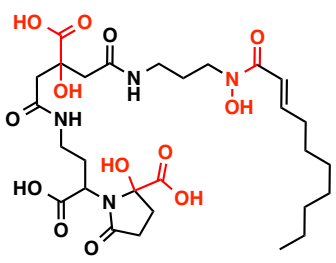

Baumannoferrin A

Scheme S1. (A) The biosynthetic gene cluster for acinetobactin. ${ }^{1}$ A. baumannii acinetobactin synthesis genes are abbreviated bas, A. baumannii acinetobactin utilization genes are abbreviated bau, and A. baumannii acinetobactin release genes are abbreviated bar. The "F" and " $T$ " circles represent putative Fur boxes and transcriptional termination signals, respectively. (B) A 
proposed biosynthetic scheme for acinetobactin. ${ }^{2,3}$ In the NRPS domains, "C" stands for condensation, "T" stands for thiolation, and "ICL" stands for isochorismate lyase. (C) A proposed scheme depicting the role of the release and utilization proteins for acinetobactin. BauA is a TonB dependent outer-membrane receptor. ${ }^{4}$ BauCDE are likely $\mathrm{ABC}$ transport components. BauF is proposed to release iron via an unkown mechanism, possibly hydrolase activity based on sequence homology, allowing the siderophore to re-enter the cycle, or covalent bond cleavage, requiring the molecule to be re-synthesized. (D) The other siderophores of $A$. baumannii, the fimsbactins (represented by fimsbactin A) and baumannoferrin.

\section{Recipe for M9 Minimal Media}

Per liter:

$\mathrm{Na}_{2} \mathrm{HPO}_{4} \bullet 7 \mathrm{H}_{2} \mathrm{O}$

$12.8 \mathrm{~g} *$

$\mathrm{KH}_{2} \mathrm{PO}_{4}$

$5 \mathrm{~g} *$

$\mathrm{NaCl}$

$0.5 \mathrm{~g}$

$\mathrm{NH}_{4} \mathrm{Cl}$

$1.0 \mathrm{~g}$

$1 \mathrm{M} \mathrm{MgSO}_{4}$ solution, filter sterilized

$2 \mathrm{~mL}$

$1 \mathrm{M} \mathrm{CaCl}_{2}$ solution, filter sterilized

$0.1 \mathrm{~mL}$

20 weight $\%$ succinate solution, filter sterilized

$20 \mathrm{~mL}$

Tap water

$978 \mathrm{~mL}$

Add the $\mathrm{Na}_{2} \mathrm{HPO}_{4} \bullet 7 \mathrm{H}_{2} \mathrm{O}, \mathrm{KH}_{2} \mathrm{PO}_{4}, \mathrm{NaCl}$, and $\mathrm{NH}_{4} \mathrm{Cl}$ as solids to the tap water. Shake to dissolve. Autoclave for 15 minutes at $15 \mathrm{psi}\left(1.05 \mathrm{~kg} / \mathrm{cm}^{2}\right)$ on liquid cycle. Once cooled to room temperature, add the $1 \mathrm{M} \mathrm{MgSO}_{4}$, the $1 \mathrm{M} \mathrm{CaCl}_{2}$, and the 20 weight $\%$ succinate and shake to mix.

* Values are for standard $\mathrm{pH}=7 \mathrm{M} 9$ minimal media. For $\mathrm{pH}$ adjusted M9, values were taken from the Phosphate Buffer Table - 0.2 M solution that can be found on the Buffer Reference Center of the Sigma-Aldrich website. 


\section{Procedures for Compound Synthesis}

All chemical synthesis was performed using reagents and solvents from commercial suppliers Alfa Aesar, Fluka, Sigma Aldrich, Chem Impex International, Nova Biochem, and BACHEM. Our ability to study the acinetobactin isomerization reaction and other properties of acinetobactin isomers required a scalable total synthesis of pre-acinetobactin 1a and acinetobactin $\mathbf{1 b}$ in stable forms. We adapted a total synthesis reported by Takeuchi and coworkers to produce the key intermediate benzyl protected pre-acinetobactin 12 (Scheme S2). Synthesis of 12 was executed in three parts. First, oxazoline benzyl ester $\mathbf{6}$ was synthesized by converting commercially available 2,3-dihydroxybenzaldehyde 3 to imidate 5 which was cyclized with L-threonine benzyl ester (Scheme S2A). Next, $N$-Boc- $O$-Bn-hydroxyhistamine 9 was prepared from commercially available histamine 7 through conversion to 4-(2-haloethyl)- $1 H$-imidazole 8 followed by $\mathrm{S}_{\mathrm{N}} 2$ displacement of the halide with $N$-Boc- $O$-Bn-hydroxylamine under strong base $(\mathrm{NaH})$ conditions (Scheme S2B). We were able to reproducibly generate grams of intermediates 6 and 9 that are stable to storage for years at $-20{ }^{\circ} \mathrm{C}$. To produce hundreds of milligrams of 12 , the protecting groups were removed from intermediates 6 and 9 in parallel and the resulting $O$-Bnhydroxylamine $\mathbf{1 0}$ was coupled to carboxylate 11 using EDC/HOBt under basic conditions to give benzyl protected pre-acinetobactin 12 (Scheme S2C). While the final amide coupling reaction was low yielding (typically $\sim 30 \%$ ) it was scalable and readily provided hundreds of milligrams of $\mathbf{1 2}$ as the TFA salt after purification by preparative HPLC. 
A.

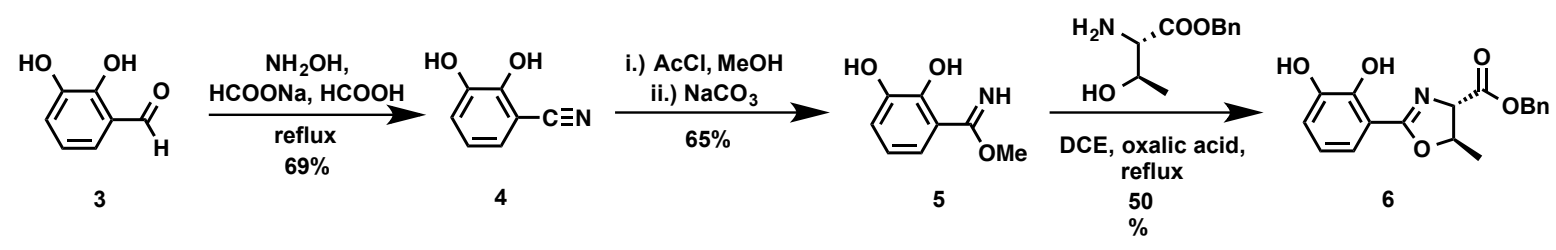

B.

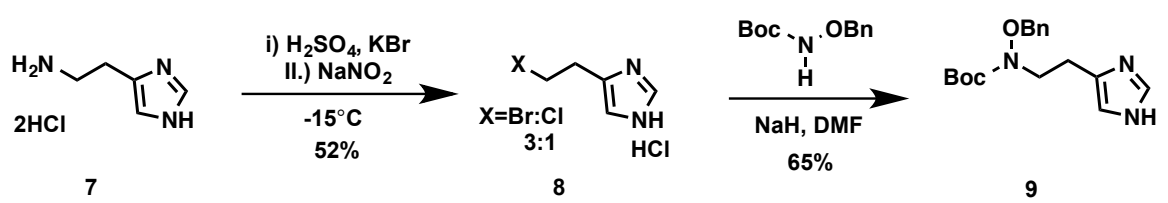

c.

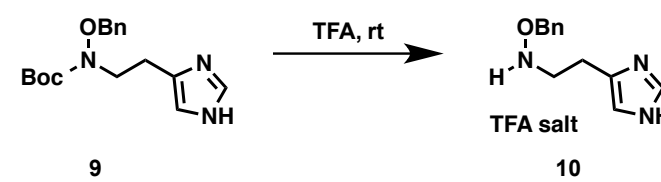

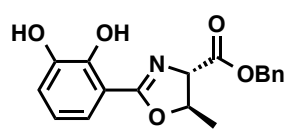

6

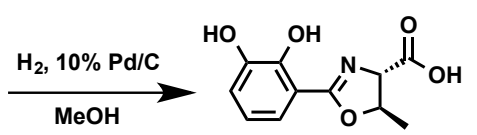

11

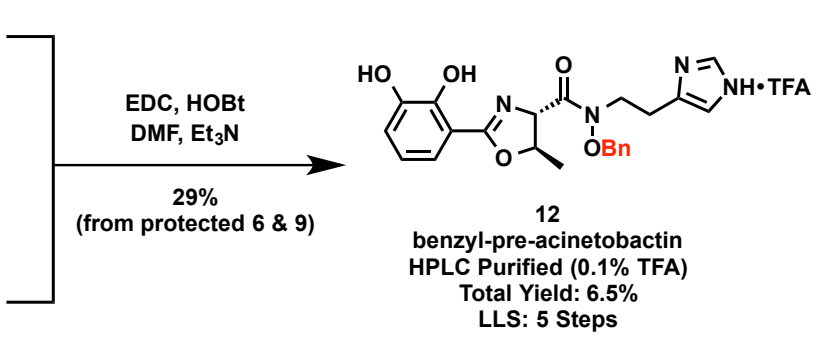

Scheme S2. The total synthesis of the key intermediate, benzyl protected pre-acinetobactin, adapted from Takeuchi and coworkers ${ }^{5}$.<smiles>N#Cc1cccc(O)c1O</smiles>

2,3-Dihydroxybenzenenitrile (4). Nitrile 1 was synthesized as described previously. ${ }^{5}$ Briefly, 2,3-dihydroxybenzaldehyde was refluxed while stirring for five hours in formic acid with 1.3 equivalents of hydroxylamine hydrochloride and 1.3 equivalents of sodium formate. The reaction mixture was diluted with ice water and neutralized with saturated sodium bicarbonate. The mixture was extracted with $\mathrm{Et}_{2} \mathrm{O}$, dried over $\mathrm{MgSO}_{4}$, and concentrated by rotary evaporation to yield an orange solid in 69\% yield. ${ }^{1} \mathrm{H}$ NMR $\left(300 \mathrm{MHz},\left(\mathrm{CD}_{3}\right)_{2} \mathrm{SO}\right) \delta(\mathrm{ppm}) 10.34-9.78$ (br. s., 2 H), 7.00 (t, $J=8.8 \mathrm{~Hz}, 2 \mathrm{H}), 6.74(\mathrm{t}, J=7.9 \mathrm{~Hz}, 1 \mathrm{H})$ 


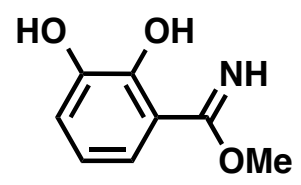

2,3-Dihydroxybenzeneimidate (5). Imidate 2 was synthesized as described previously. ${ }^{5}$ Briefly, nitrile 1 was dissolved in roughly 48 equivalents of freshly distilled methanol and sealing under argon gas. An argon balloon was fit to the septa as a vent. Using a syringe, roughly 32 equivalents of acetyl chloride were added dropwise, causing heat and the evolution of gas into the vent balloon. The mixture was stirred for 48 hours and turned dark orange. The mixture was cooled in an ice bath and neutralized with saturated sodium bicarbonate. The aqueous mixture was extracted with $\mathrm{Et}_{2} \mathrm{O}$ and the organic layer was washed with water and brine, dried over $\mathrm{MgSO}_{4}$, and concentrated by rotary evaporation to yield a yellow-brown solid in $65 \%$ yield. ${ }^{1} \mathrm{H}$ NMR ${ }^{1} \mathrm{H}$ NMR (300MHz, $\left.\left(\mathrm{CD}_{3}\right)_{2} \mathrm{SO}\right) \delta(\mathrm{ppm}) 9.04$ (br. s., $\left.1 \mathrm{H}\right), 8.72$ (br. s., $\left.1 \mathrm{H}\right), 7.10$ (dd, $J=$ $1.2,8.2 \mathrm{~Hz}, 1 \mathrm{H}), 6.81$ (dd, $J=1.2,7.6 \mathrm{~Hz}, 1 \mathrm{H}), 6.56-6.48(\mathrm{~m}, 1 \mathrm{H}), 3.84(\mathrm{~s}, 3 \mathrm{H})$

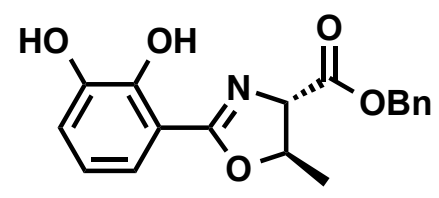

Benzyl protected oxazoline (6). Oxazoline 3 was synthesized as described previously. ${ }^{5}$ Briefly, imidate 2 was refluxed with 1 equivalent of O-benzyl-L-threonine:oxalate in 1,2 dichloroethane overnight. The reaction mixture was allowed to cool and concentrated by rotary evaporation. The concentrated mixture was dissolved into 5\% citric acid and extracted with ethyl acetate. The organic layer was washed with water and brine, concentrated by rotary evaporation and purified on a normal phase silica gel column with a gradient of ethyl acetate and hexanes. Fractions containing product were concentrated by rotary evaporation to yield a viscous, dark brown oil in $50 \%$ yield. ${ }^{1} \mathrm{H}$ NMR $\left(300 \mathrm{MHz},\left(\mathrm{CD}_{3}\right)_{2} \mathrm{SO}\right) \delta(\mathrm{ppm}) 11.90$ (br. s., $\left.1 \mathrm{H}\right), 9.27$ (s, $\left.1 \mathrm{H}\right), 7.40-7.32$ (m, 5 H), 7.05 (dd, $J=1.5,7.9 \mathrm{~Hz}, 1 \mathrm{H}), 6.96(\mathrm{dd}, J=1.5,7.9 \mathrm{~Hz}, 1 \mathrm{H}), 6.77-6.69$ (m, $1 \mathrm{H})$, $5.20(\mathrm{~d}, J=1.8 \mathrm{~Hz}, 2 \mathrm{H}), 5.08-4.97(\mathrm{~m}, 1 \mathrm{H}), 4.77(\mathrm{~d}, J=6.4 \mathrm{~Hz}, 1 \mathrm{H}), 1.46(\mathrm{~d}, J=6.4 \mathrm{~Hz}, 3 \mathrm{H})$ 


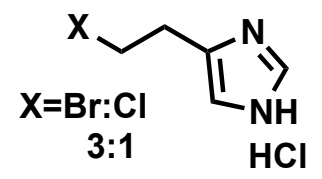

2-Bromo(Chloro)ethyl-imidazole (8). Imidazole 5 was synthesized as described previously. ${ }^{5}$ Briefly, histamine dihydrochloride* was stirred with roughly 3 equivalents of potassium bromide in $1.5 \mathrm{M}$ sulfuric acid $\left(8 \mathrm{~mL} /\right.$ gram of histamine salt) and the solution was cooled to $-15^{\circ} \mathrm{C}$. A saturated solution of sodium nitrite $(0.7 \mathrm{~mL} /$ gram of histamine $)$ was added all at once, causing the solution to change from colorless to orange-brown. The mixture was stirred cold for 30 minutes and then allowed to warm to room temperature while stirring. After $\sim 2.5$ hours, the mixture changed from orange-brown to pale yellow and was cooled again to $-15^{\circ} \mathrm{C}$. The $\mathrm{pH}$ of the solution was brought to 10 with $5 \mathrm{M} \mathrm{NaOH}$, and the basic solution was extracted with chloroform. A $0.5 \mathrm{~N} \mathrm{HCl} /$ ethyl acetate solution was prepared (12 $\mathrm{mL} /$ gram of histamine) and the chloroform layer was added to this solution. The product was concentrated by rotary evaporation to yield a white-brown cake like solid in $52 \%$ yield. ${ }^{*}$ Working with histamine can evoke an immune response/sensitization. Utilize appropriate safety precautions. ${ }^{1} \mathrm{H}$ NMR $\left(300 \mathrm{MHz}, \mathrm{D}_{2} \mathrm{O}\right)$ $\delta(\mathrm{ppm}) 8.46(\mathrm{~d}, J=1.2 \mathrm{~Hz}, 1 \mathrm{H}), 7.21(\mathrm{~s}, 1 \mathrm{H}), 3.69(\mathrm{t}, J=6.4 \mathrm{~Hz}, 1 \mathrm{H}), 3.58$ - $3.52(\mathrm{~m}, 3 \mathrm{H})$, $3.17(\mathrm{t}, J=6.4 \mathrm{~Hz}, 3 \mathrm{H}), 3.06(\mathrm{t}, J=5.9 \mathrm{~Hz}, 1 \mathrm{H})$

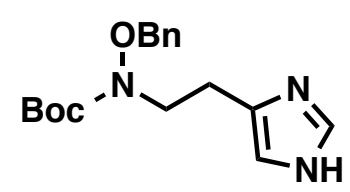

$\boldsymbol{N}$-Boc-O-Benzylhydroxyhistamine (9). Hydroxyhistamine 6 was prepared as described previously. ${ }^{5}$ Briefly, N-Boc-OBn-Hydroxyhistamine was stirred in anhydrous DMF at $0^{\circ} \mathrm{C}$ and 3 equivalents of sodium hydride ( $60 \%$ in oil) were added as a solid. The reaction mixture was allowed to warm to room temperature and stirred under argon atmosphere. After 30 minutes, 1 equivalent of imidazole $\mathbf{5}$ was added as a solid, causing bubbling and evolution of heat. The mixture was put back under argon and allowed to react overnight. The reaction mixture was concentrated by rotary evaporation to a red-brown sludge, which was purified by reverse-phase liquid chromatography (gradient from $100 \%$ water to $100 \%$ acetonitrile) to give a yellow oil in a $65 \%$ yield. ${ }^{1} \mathrm{H}$ NMR $\left(300 \mathrm{MHz}, \mathrm{CDCl}_{3}\right) \delta(\mathrm{ppm}) 8.36(\mathrm{~s}, 1 \mathrm{H}), 7.35(\mathrm{~s}, 5 \mathrm{H}), 6.92(\mathrm{~s}, 1 \mathrm{H}), 4.80$ (s, $2 \mathrm{H}), 3.74(\mathrm{t}, J=6.4 \mathrm{~Hz}, 2 \mathrm{H}), 2.94(\mathrm{t}, J=6.4 \mathrm{~Hz}, 2 \mathrm{H}), 1.43(\mathrm{~s}, 5 \mathrm{H})$ 


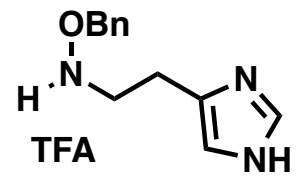

$\boldsymbol{O}$-Benzylhydroxyhistamine TFA salt (10). Hydroxyhistamine 7 was prepared as described previously. ${ }^{5}$ Briefly, hydroxyhistamine 6 was dissolved in excess trifluoroacetic acid and allowed to react, open to air, for 1 hour. The product was concentrated by rotary evaporation and immediately taken on to the synthesis of $\mathbf{8}$.<smiles>CC1OC(c2cccc(O)c2O)=N[C@@H]1C(=O)O</smiles>

Carboxy oxazoline (11). Oxazoline 4 was synthesized as described previously. ${ }^{5}$ Briefly, oxazoline 3 was stirred in methanol with $\sim 1 / 10$ mass equivalent of $10 \% \mathrm{Pd} / \mathrm{C}$ under hydrogen atmosphere. Once the reaction was complete by LC-MS (1 hour), the reaction mixture was flushed with argon gas, the solid catalyst was filtered off, and the product was concentrated by rotary evaporation. The product was immediately taken on to the synthesis of $\mathbf{8}$.<smiles>CC1OC(c2cccc(O)c2O)=N[C@@H]1C(=O)N(CCc1cn([C+](C)(F)F)cn1)OCc1ccccc1</smiles>

$\boldsymbol{O}$-Benzyl-Pre-acinetobactin TFA salt (12). Benzyl protected pre-acinetobactin 8 was prepared as described previously. ${ }^{5}$ Briefly, oxazoline $\mathbf{4}$ and hydroxyhistamine 7 were dissolved in anhydrous DMF with 4 equivalents of EDC and 4 equivalents of HOBt. The mixture was made basic with $\mathrm{NEt}_{3}$, put under inert atmosphere, and allowed to react overnight. The reaction mixture was concentrated by rotary evaporation, and the crude sludge was purified by preparatory HPLC. The TFA salt was isolated as a pale oil in 52\% yield over 2 steps from the protected starting materials 3 and 6. ${ }^{1} \mathrm{H}$ NMR (300MHz, $\left.\left(\mathrm{CD}_{3}\right)_{2} \mathrm{SO}\right) \delta$ (ppm) 11.90 (br. s., $\left.1 \mathrm{H}\right)$, $9.27(\mathrm{~s}, 1 \mathrm{H}), 7.40-7.32(\mathrm{~m}, 5 \mathrm{H}), 7.05(\mathrm{dd}, J=1.5,7.9 \mathrm{~Hz}, 1 \mathrm{H}), 6.96$ (dd, $J=1.5,7.9 \mathrm{~Hz}, 1 \mathrm{H})$, 6.77 - 6.69 (m, $1 \mathrm{H}), 5.20(\mathrm{~d}, J=1.8 \mathrm{~Hz}, 2 \mathrm{H}), 5.08-4.97(\mathrm{~m}, 1 \mathrm{H}), 4.77(\mathrm{~d}, J=6.4 \mathrm{~Hz}, 1 \mathrm{H})$, $1.46(\mathrm{~d}, J=6.4 \mathrm{~Hz}, 3 \mathrm{H})$ 
III. Kinetic UV-Vis Spectra of Acinetobactin Isomerization

A.

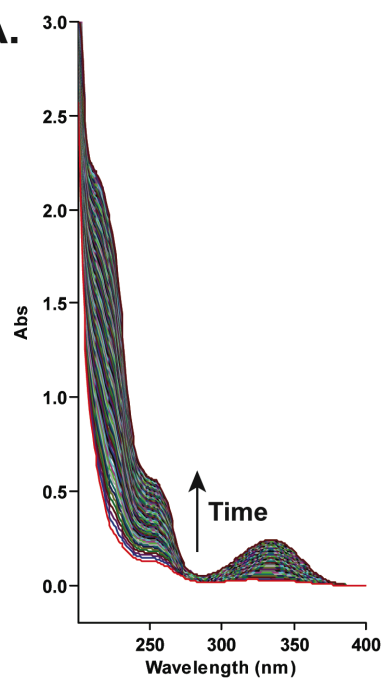

C.

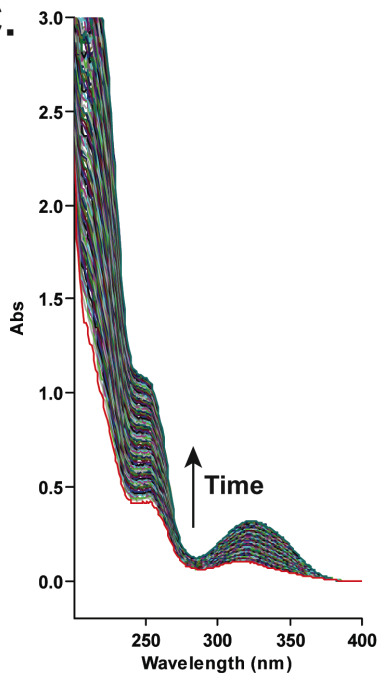

E.

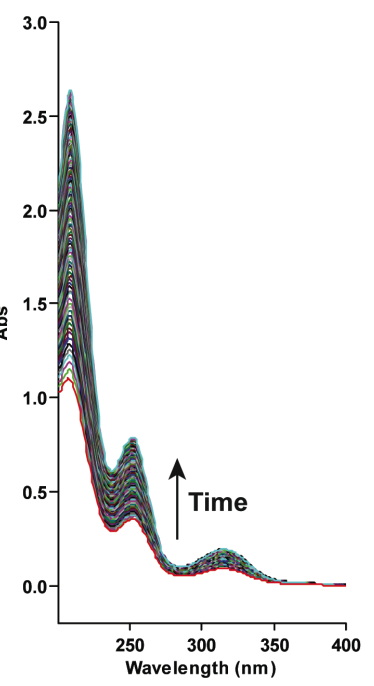

B.

pH 4.6

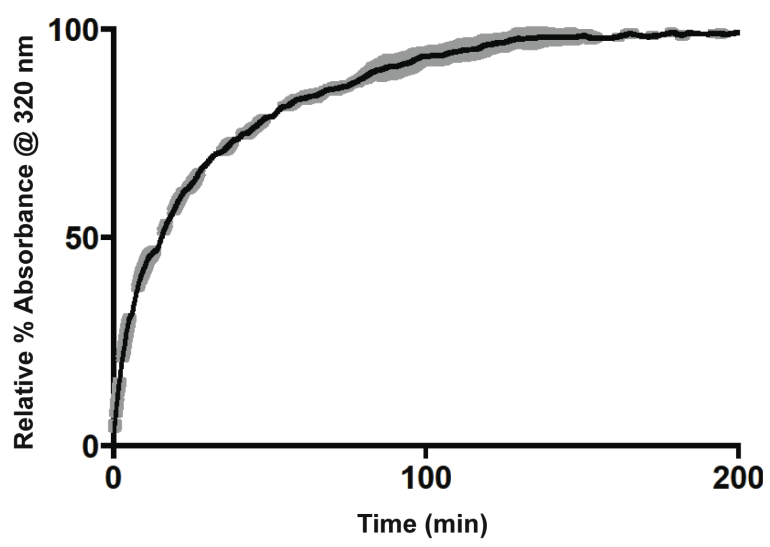

D.

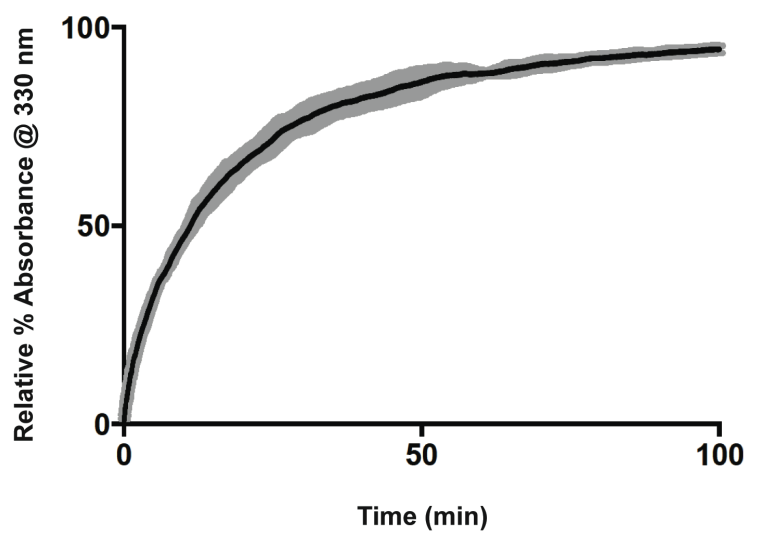

F.

pH 8.8

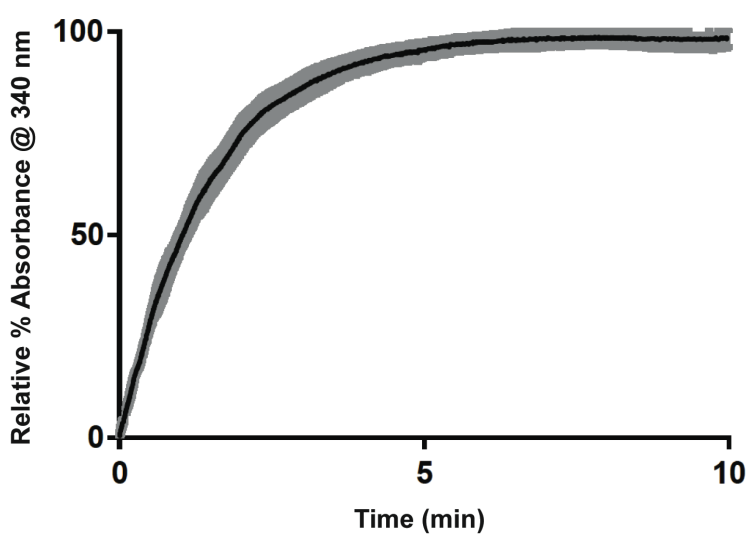


Figure S1. Kinetic UV-Vis analysis of pre-acinetobactin isomerization in phosphate buffers. Aqueous solutions of pre-acinetobactin in $250 \mu \mathrm{L}$ total volume were prepared using $0.1 \mathrm{M}$ potassium phosphate buffers at $\mathrm{pH} 4.6,7.0$, and 8.8 in a quartz cuvette. Scanning kinetics were performed at $37^{\circ} \mathrm{C}$ over the wavelength range of $200 \mathrm{~nm}-400 \mathrm{~nm}$ for $\mathrm{pH} 4.6$ (A), 7.0 (C), and 8.8 (D). Single wavelength kinetic experiments were performed at wavelengths selected based on the scanning kinetic experiments for each $\mathrm{pH}$ value $(\mathrm{pH}$ 4.6, $320 \mathrm{~nm}, \mathbf{B} ; \mathrm{pH} 7.0,330 \mathrm{~nm}, \mathbf{D} ; \mathrm{pH}$ $8.8,340 \mathrm{~nm}, \mathbf{F})$. Plots of relative percent absorbance at selected single wavelengths versus time generated exponential growth curves with relative rates that matched the kinetic ${ }^{1} \mathrm{H}-\mathrm{NMR}$ experiments (Figures S3-S11); relative rate of isomerization: $8.8>>7.0>4.6$. Single wavelength experiments were performed in triplicate with standard deviations represented as the grey shadowing around the black curves in panels $\mathbf{B}, \mathbf{D}$, and $\mathbf{F}$.

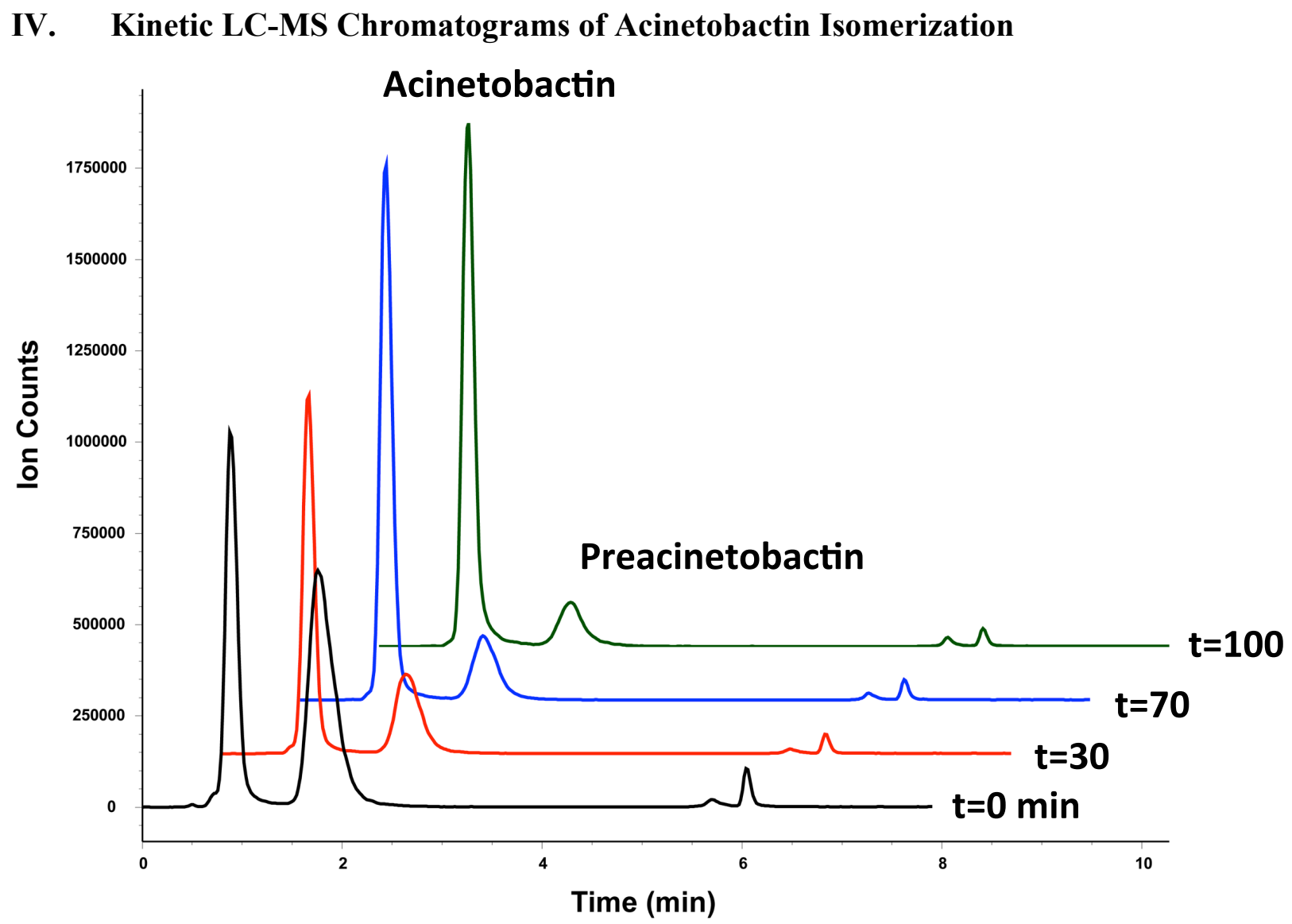

Figure S2. Example of LC-MS kinetic analysis of pre-acinetobactin isomerization in $0.1 \mathrm{M}$ phosphate buffer at $\mathrm{pH}$ 4.6. LC-MS experiments matched general trends observed in the NMR and UV-Vis kinetic studies; relative rate of isomerization: $8.8>>7.0>4.6$. 

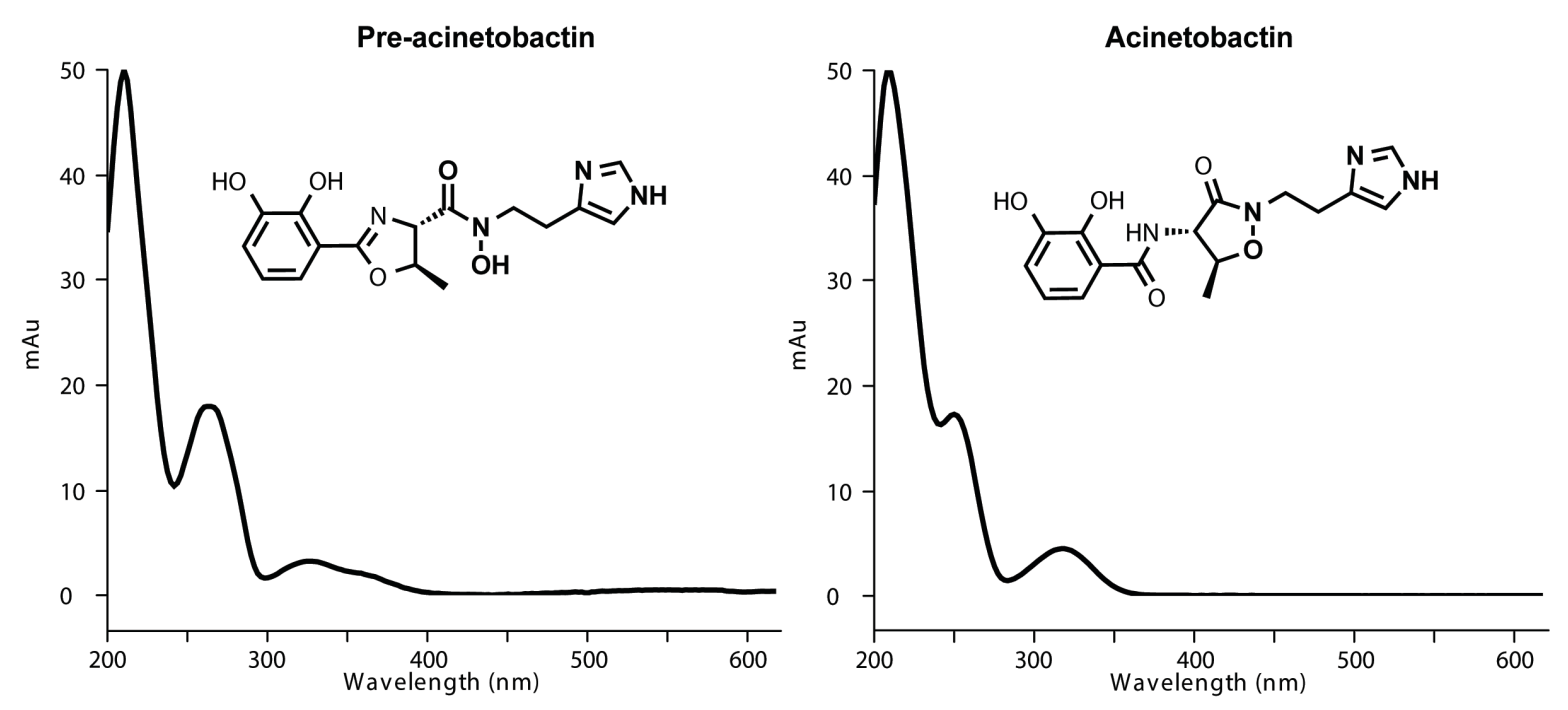

Figure S3. UV-Vis spectra of pre-acinetobactin (left) and acinetobactin (right) from the diode array of LC-MS. Spectra matched those from literature and allowed for the differentiation of the two signals on the chromatogram by a diagnostic peak shift from $260 \mathrm{~nm}$ (pre-acinetobactin) to 250 (acinetobactin).

\section{Kinetic ${ }^{1} \mathrm{H}-\mathrm{NMR}$ Spectra of Acinetobactin Isomerization}

General Procedure: One milligram of preacinetobactin TFA salt was isolated and dissolved in $0.6 \mathrm{~mL}$ of $90 \% \mathrm{D}_{2} \mathrm{O} / 10 \% \mathrm{H}_{2} \mathrm{O}$ buffered with $0.1 \mathrm{~mL}$ phosphates to $\mathrm{pH} 5.5,7$, or 8 . The solution was immediately vortexed and transferred to an NMR tube. Using a $500 \mathrm{MHz} \mathrm{NMR}$ at room temperature $\left(27^{\circ} \mathrm{C}\right)$, spectra were taken at preset time points* and the integration of the preacinetobactin methyl peak and the acinetobactin methyl peak were recorded. The integration ratio of preacinetobactin methyl over the total integration of both methyls was plotted against time. The natural log of this ratio was also plotted against time, and the slope of this plot was taken to be the first-order rate constant of isomerization.

* For all trials at pH 5.5 and 7, spectra were taken as an average of 32 scans and a spectrum was collected every 10 minutes. For trial 1 at $\mathrm{pH} 8$, spectra were taken as an average of 8 scans and a spectrum was collected every 40 seconds. For trials 2 and 3 at pH 8, spectra were taken as an average of 20 scans and a spectrum was collected every 2 minutes. Time windows for the plots were selected to minimize baseline noise. All reported kinetic constants are derived from an average of three independent experiments. 


\section{pH 5.5, Trial \#1}

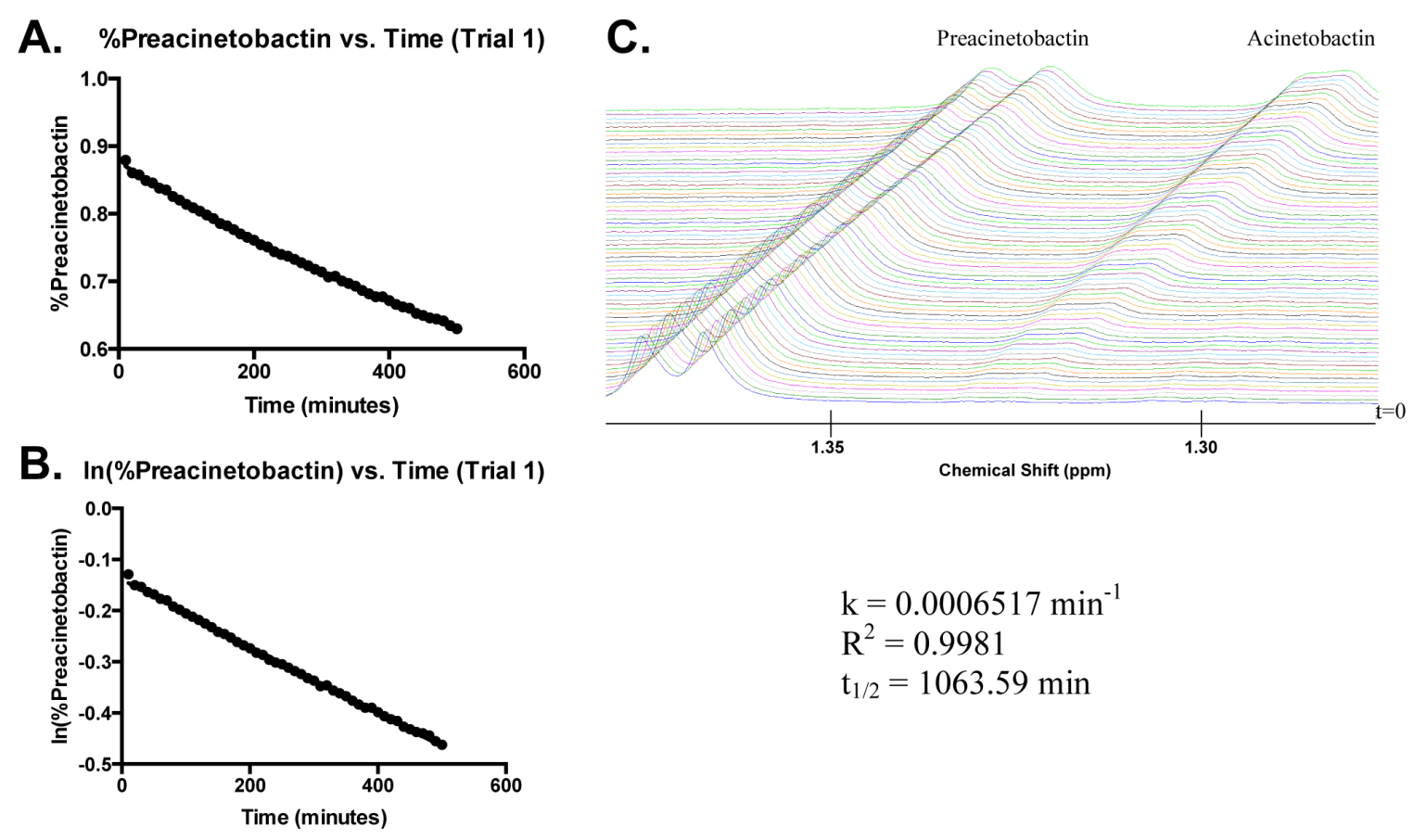

Figure S4. Trial \#1: Isomerization of pre-acinetobactin to acinetobactin at $\mathrm{pH} 5.5$.

\section{pH 5.5, Trial \#2}

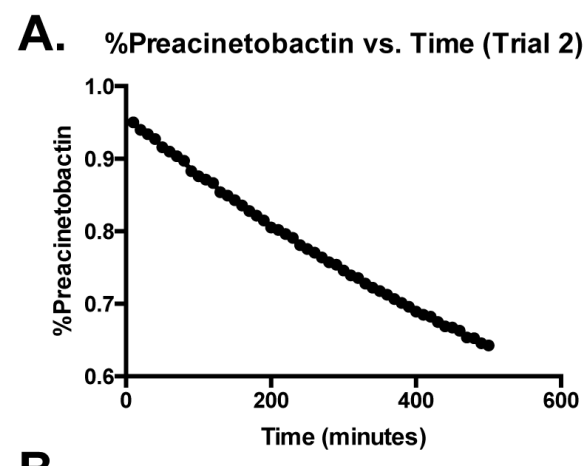

B. In(\%Preacinetobactin) vs. Time (Trial 2)
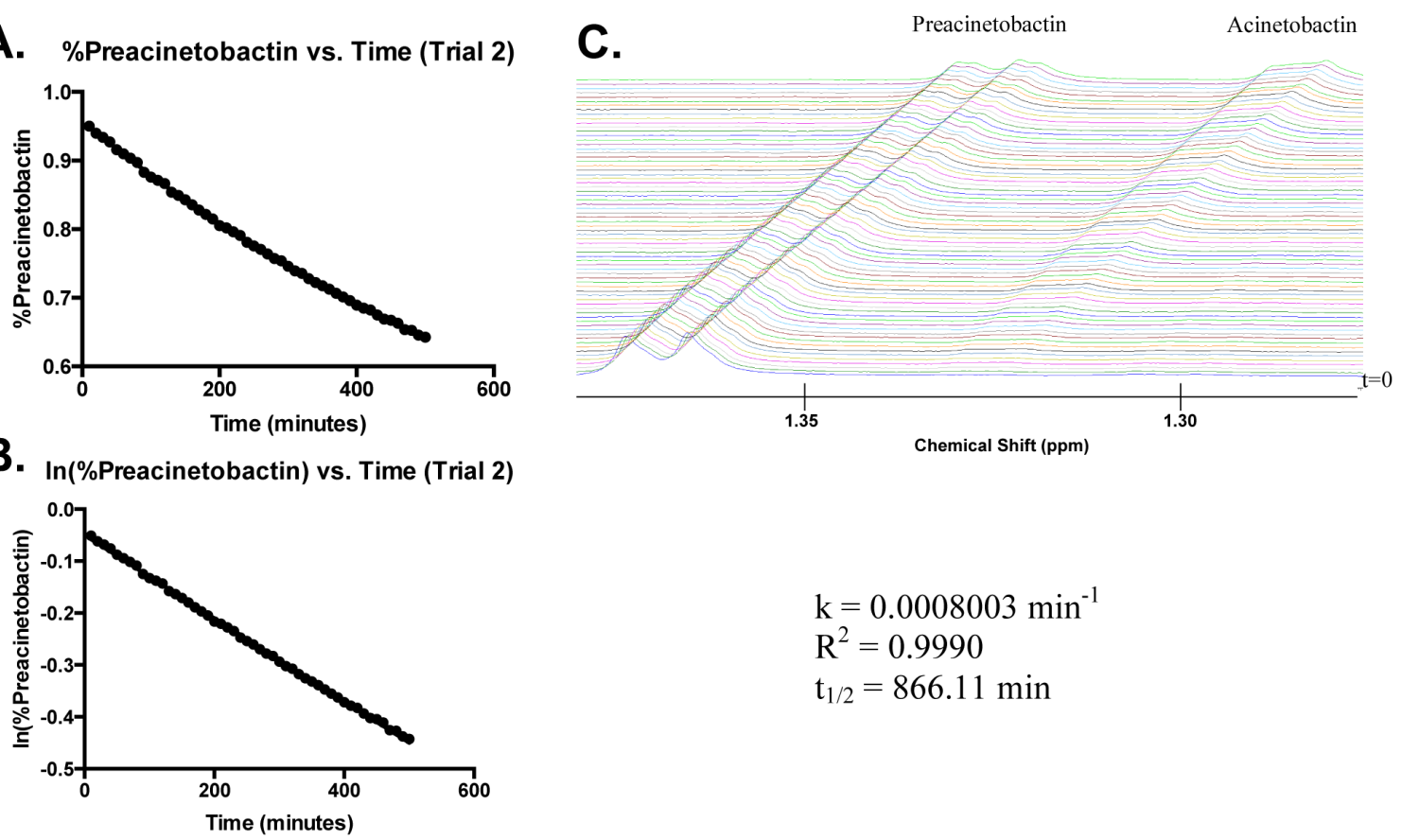

$$
\begin{aligned}
& \mathrm{k}=0.0008003 \mathrm{~min}^{-1} \\
& \mathrm{R}^{2}=0.9990 \\
& \mathrm{t}_{1 / 2}=866.11 \mathrm{~min}
\end{aligned}
$$

Figure S5. Trial \#2: Isomerization of pre-acinetobactin to acinetobactin at $\mathrm{pH} 5.5$. 


\section{pH 5.5, Trial \#3}

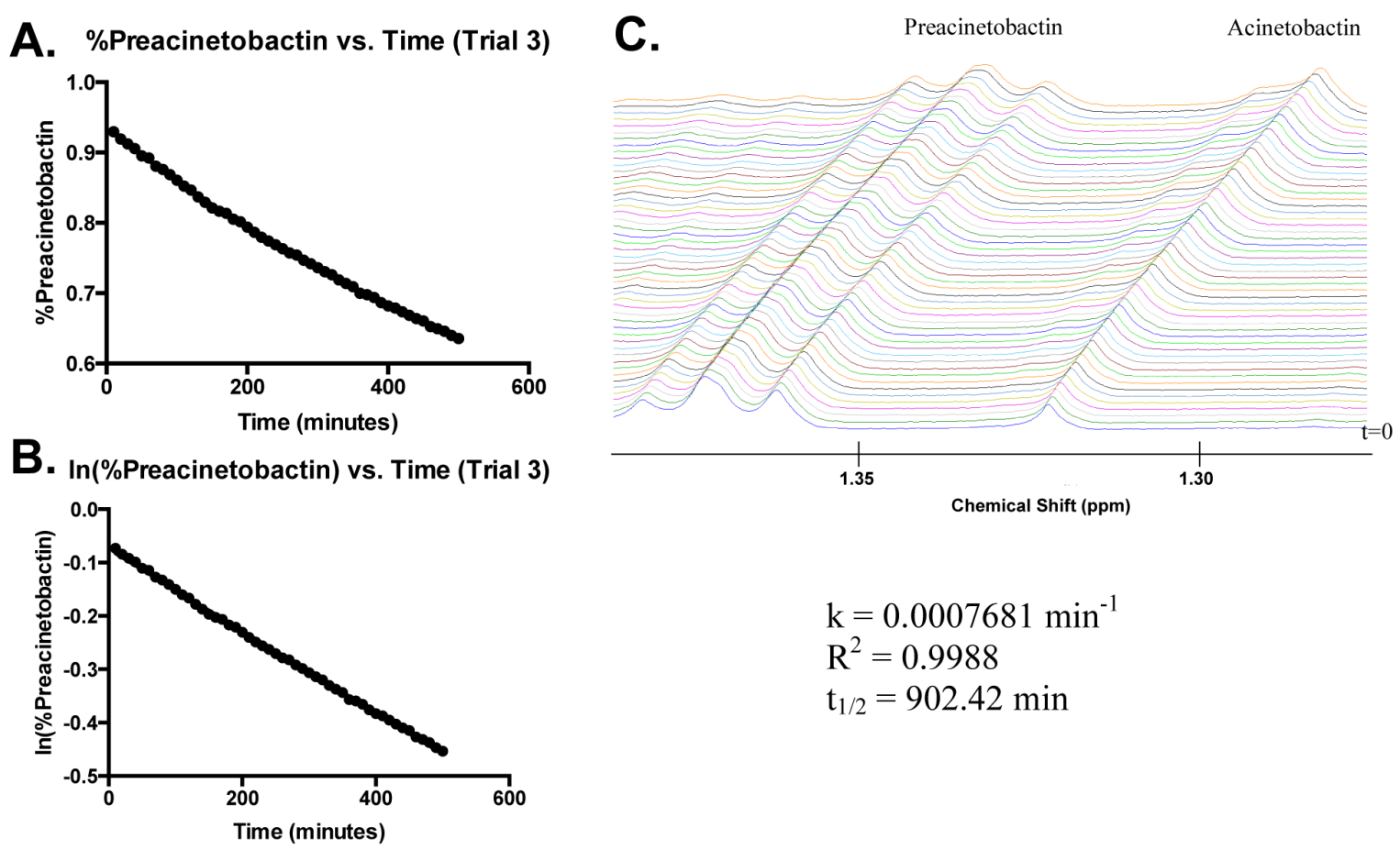

Figure S6. Trial \#3: Isomerization of pre-acinetobactin to acinetobactin at pH 5.5.

\section{pH 7.0, Trial \#1}

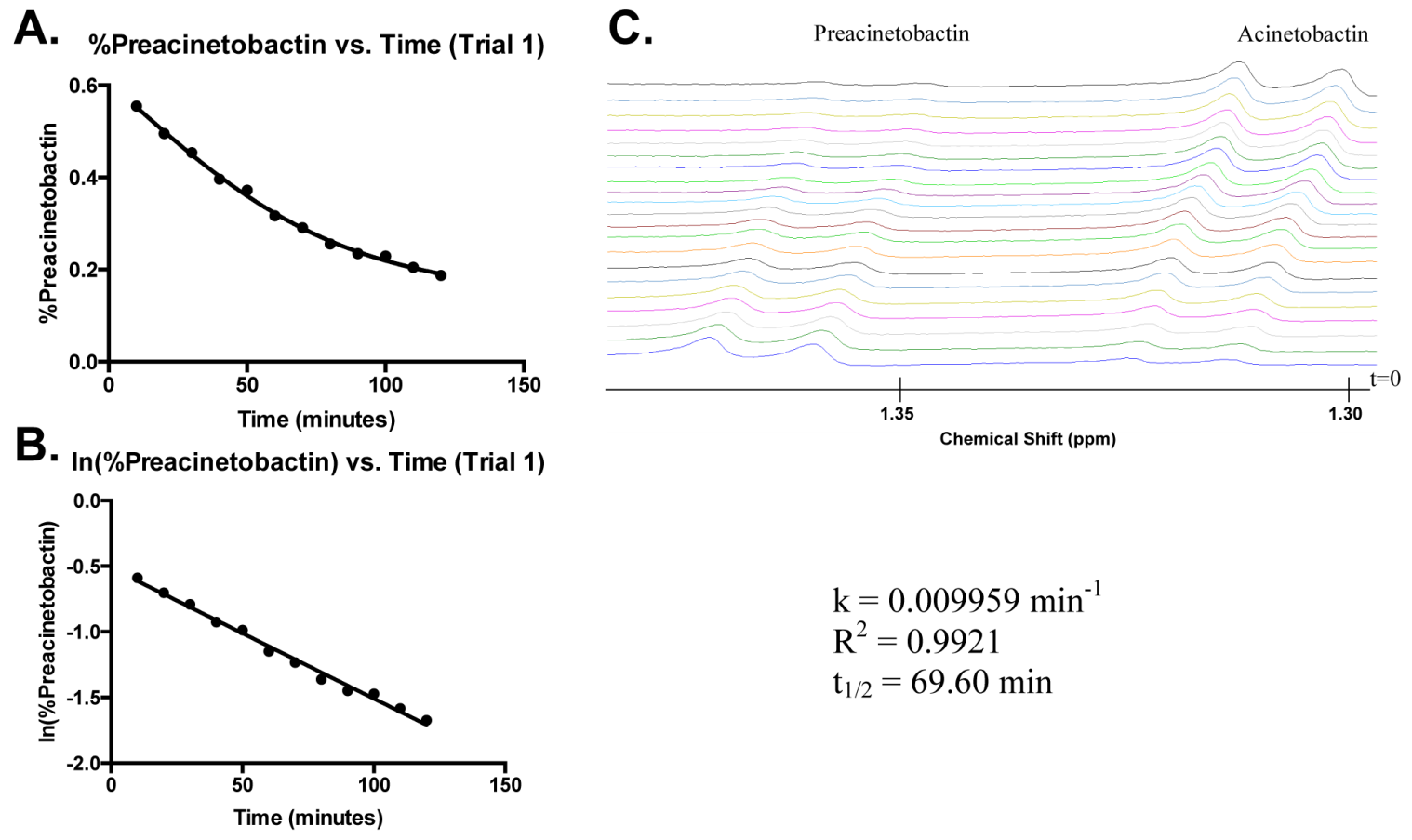

Figure S7. Trial \#1: Isomerization of pre-acinetobactin to acinetobactin at $\mathrm{pH}$ 7.0. 


\section{pH 7.0, Trial \#2}

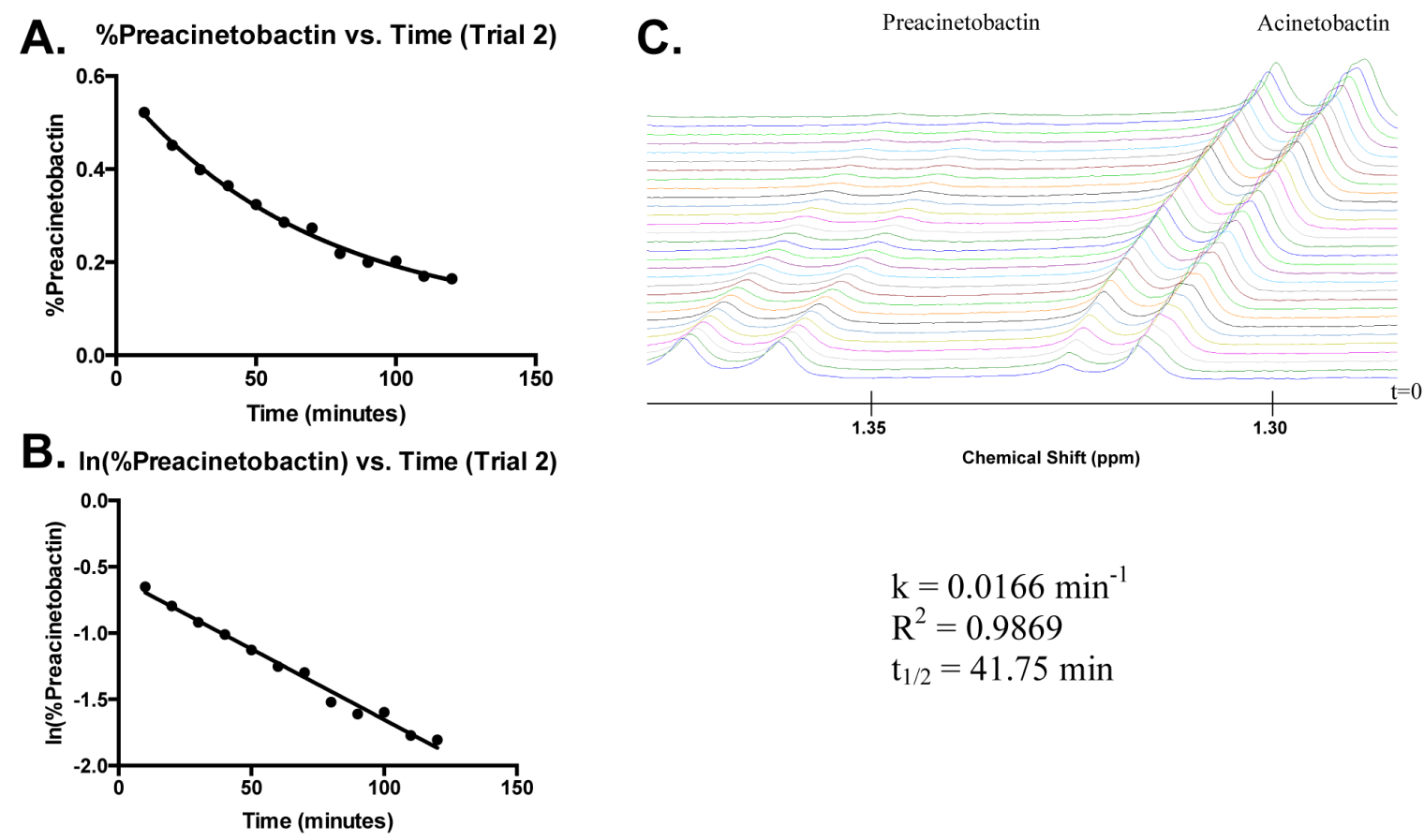

Figure S8. Trial \#2: Isomerization of pre-acinetobactin to acinetobactin at $\mathrm{pH}$ 7.0.

\section{pH 7.0, Trial \#3}

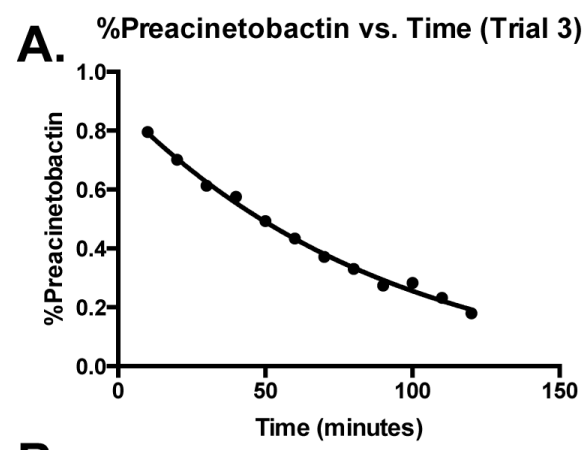

B. In(\%Preacinetobactin) vs. Time (Trial 3)
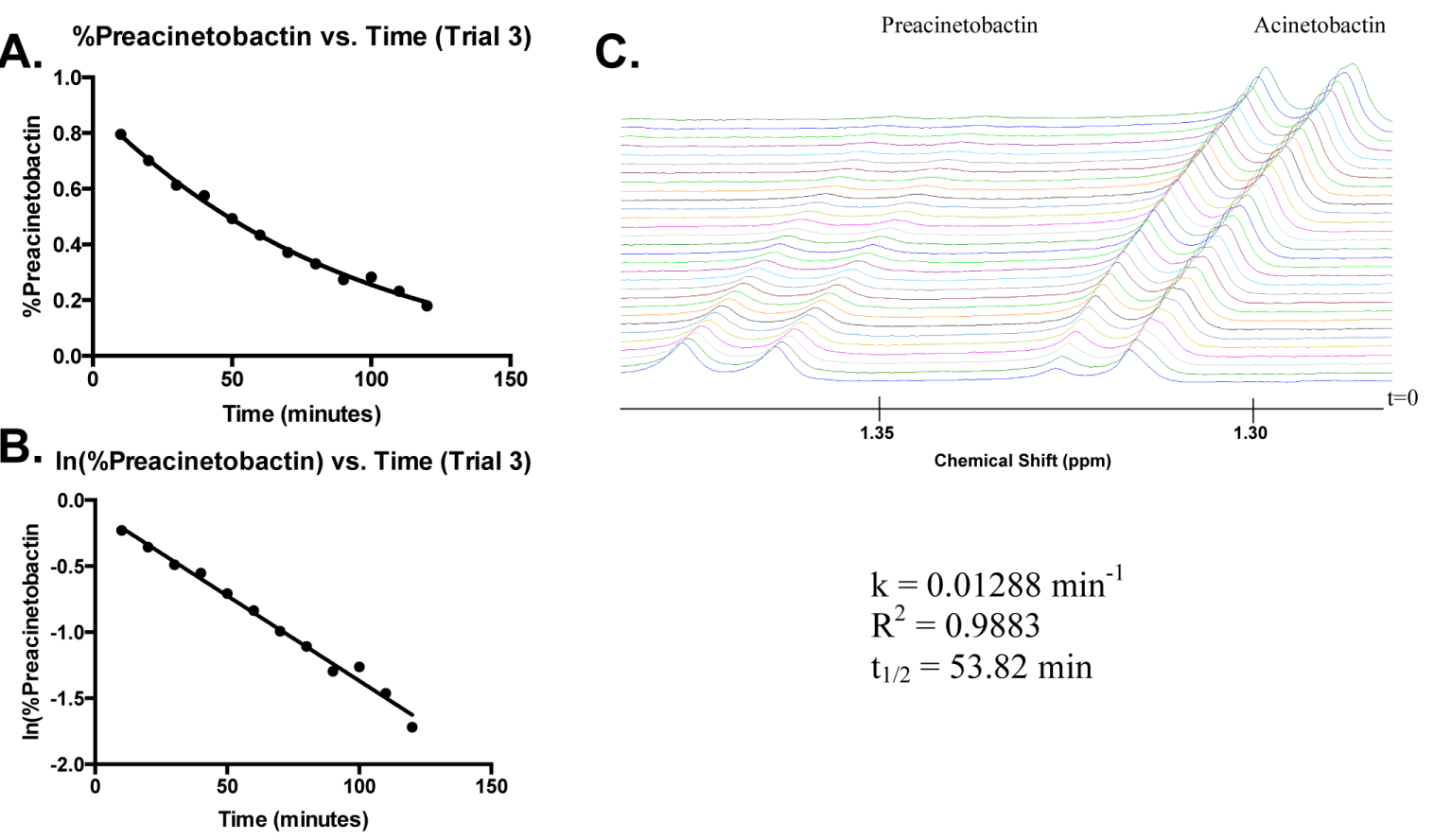

$\mathrm{k}=0.01288 \mathrm{~min}^{-1}$

$\mathrm{R}^{2}=0.9883$

$\mathrm{t}_{1 / 2}=53.82 \mathrm{~min}$

Figure S9. Trial \#3: Isomerization of pre-acinetobactin to acinetobactin at $\mathrm{pH}$ 7.0. 


\section{pH 8.0, Trial \#1}
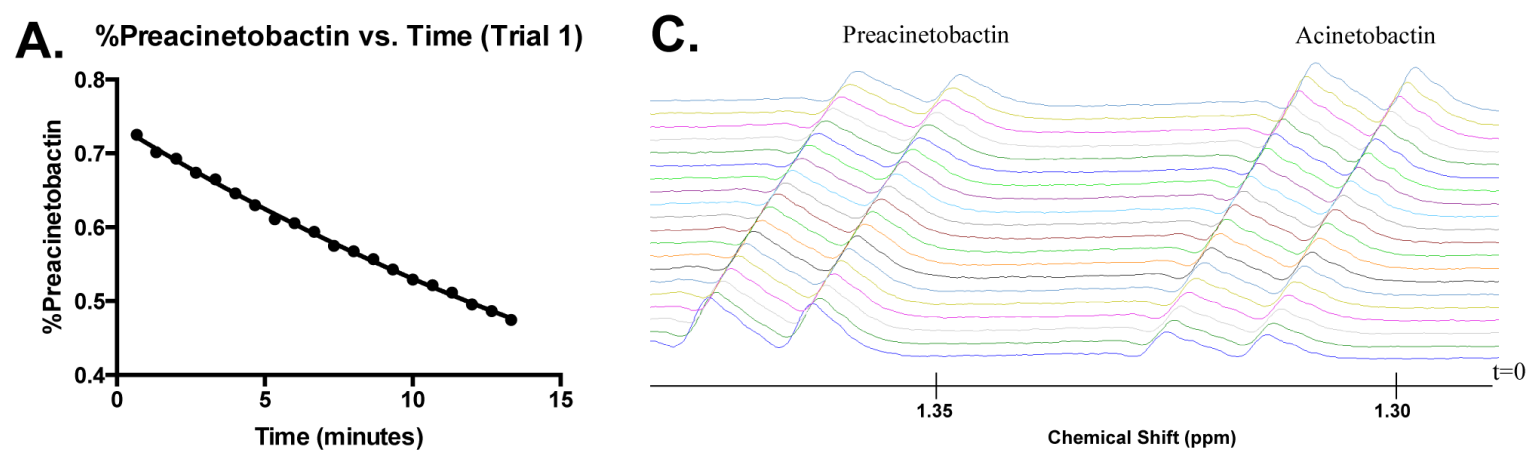

B. In(\%Preacinetobactin) vs. Time (Trial 1)

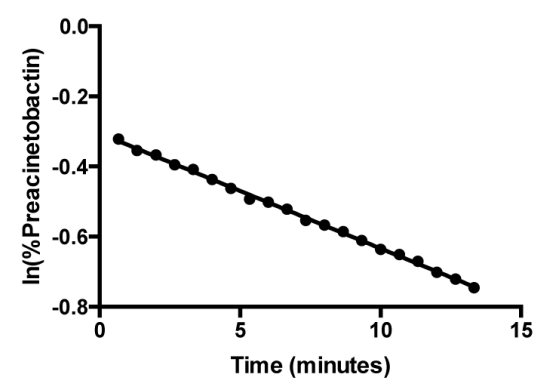

$\mathrm{k}=0.03282 \mathrm{~min}^{-1}$

$\mathrm{R}^{2}=0.9985$

$\mathrm{t}_{1 / 2}=21.12 \mathrm{~min}$

Figure S10. Trial \#1: Isomerization of pre-acinetobactin to acinetobactin at $\mathrm{pH}$ 8.0.

\section{pH 8.0, Trial \#2}

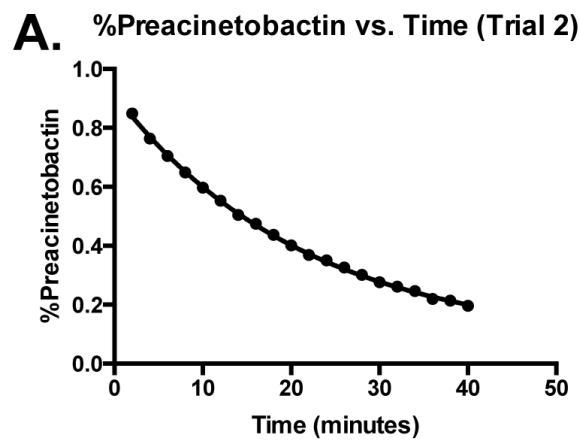

B. In(\%Preacinetobactin) vs. Time (Trial 2)
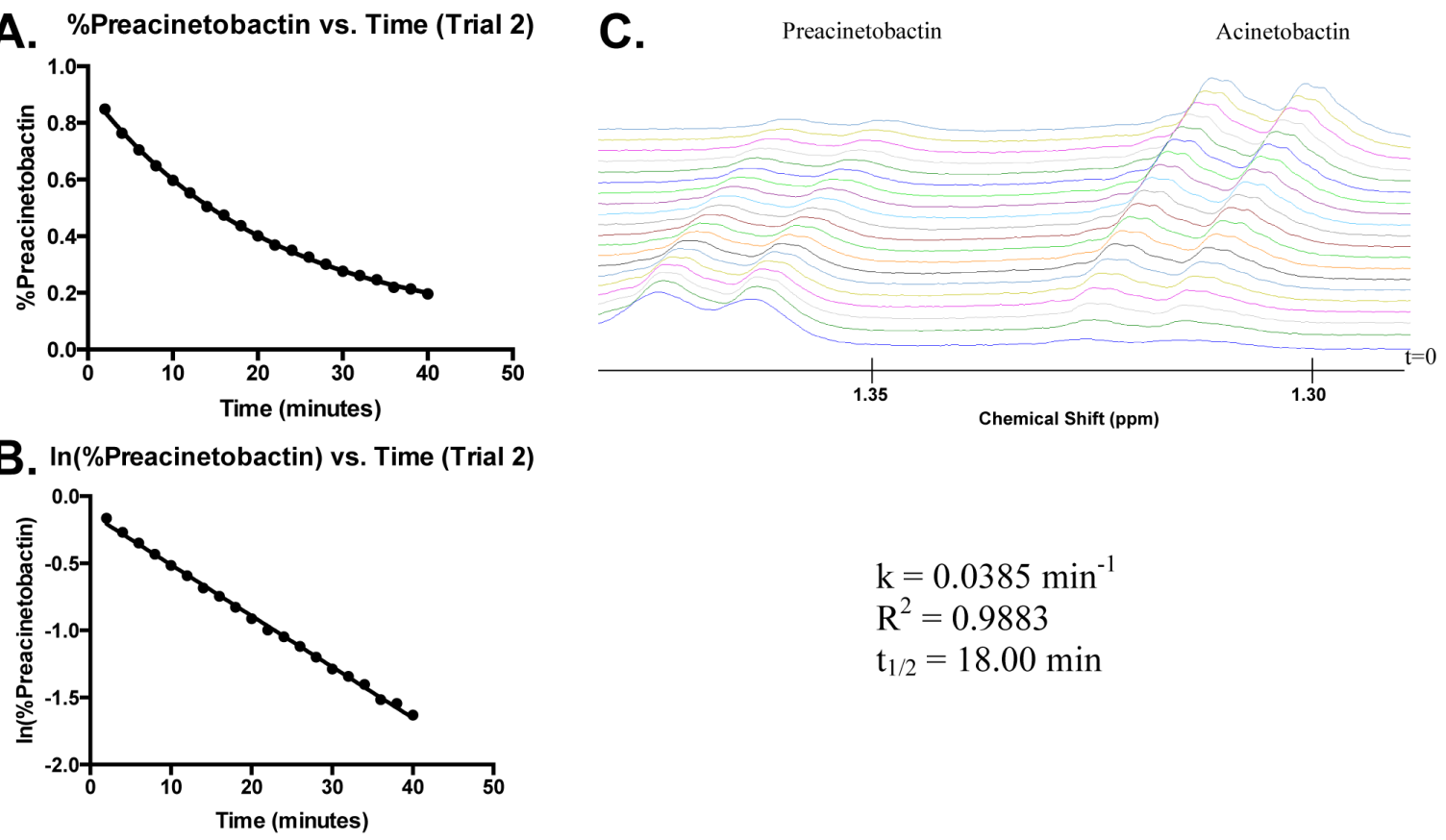

$$
\begin{aligned}
& \mathrm{k}=0.0385 \mathrm{~min}^{-1} \\
& \mathrm{R}^{2}=0.9883 \\
& \mathrm{t}_{1 / 2}=18.00 \mathrm{~min}
\end{aligned}
$$

Figure S11. Trial \#2: Isomerization of pre-acinetobactin to acinetobactin at $\mathrm{pH} 8.0$. 


\section{pH 8.0, Trial \#3}

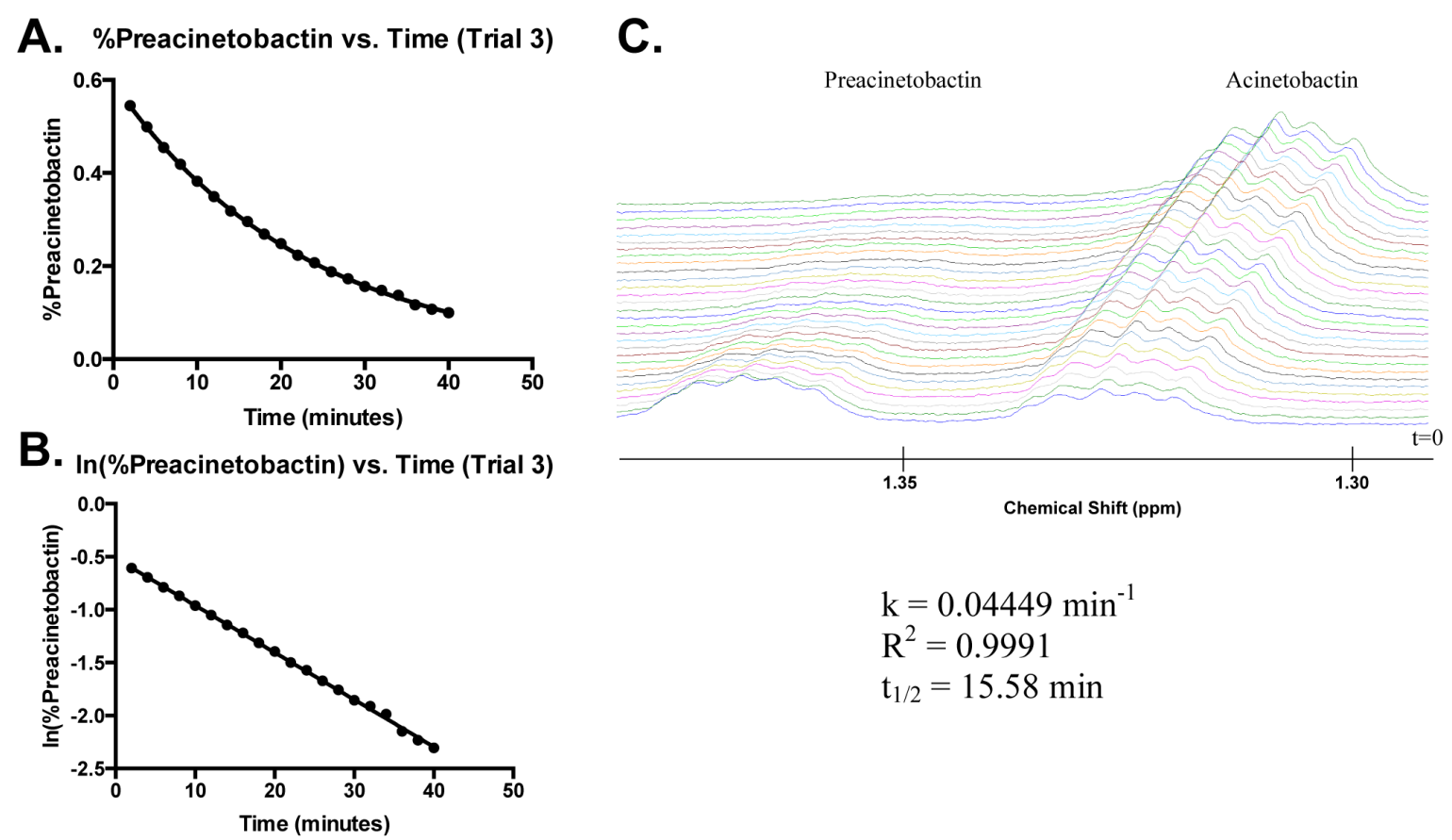

Figure S12. Trial \#3: Isomerization of pre-acinetobactin to acinetobactin at $\mathrm{pH} 8.0$.

Table S1. Average Half-Lives and Standard Deviations for Pre-Acinetobactin Isomerization

\begin{tabular}{l|ll|}
\hline Buffer $\mathrm{pH}$ & Half-Life $(\mathrm{min})$ & Standard Deviation $(\mathrm{min})$ \\
\hline $\mathrm{pH}=5.5,10 \% \mathrm{D}_{2} \mathrm{O}(3$ trials $)$ & 944 & 105 \\
$\mathrm{pH}=7.0,10 \% \mathrm{D}_{2} \mathrm{O}(3$ trials $)$ & 55 & 14 \\
$\mathrm{pH}=8.0,10 \% \mathrm{D}_{2} \mathrm{O}(3$ trials $)$ & 18 & 3 \\
$\mathrm{pH}=7.0,100 \% \mathrm{D}_{2} \mathrm{O}(2$ trials $)$ & 105 & 1 \\
\hline
\end{tabular}




\section{CD Spectra of Acinetobactin Samples}

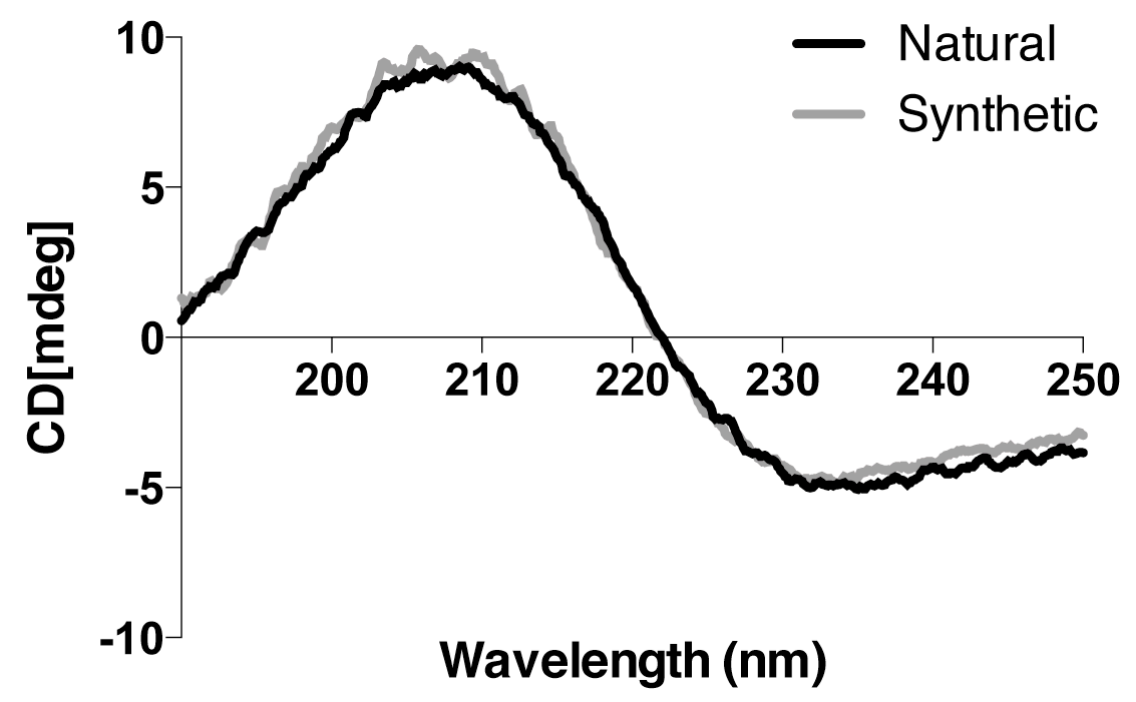

Figure S13. CD spectrum of natural acinetobactin (black trace) isolated from A. baumannii ATCC 17978 and synthetic acinetobactin (gray trace) prepared by the method shown in Scheme 1 of the main text. CD spectra were obtained on $25 \mu \mathrm{M}$ acinetobactin solutions in methanol using a Jasco-J715 spectropolarimeter in a cuvette with a $1 \mathrm{~cm}$ path length. 


\section{High-Res MS-MS of Pure Compounds}

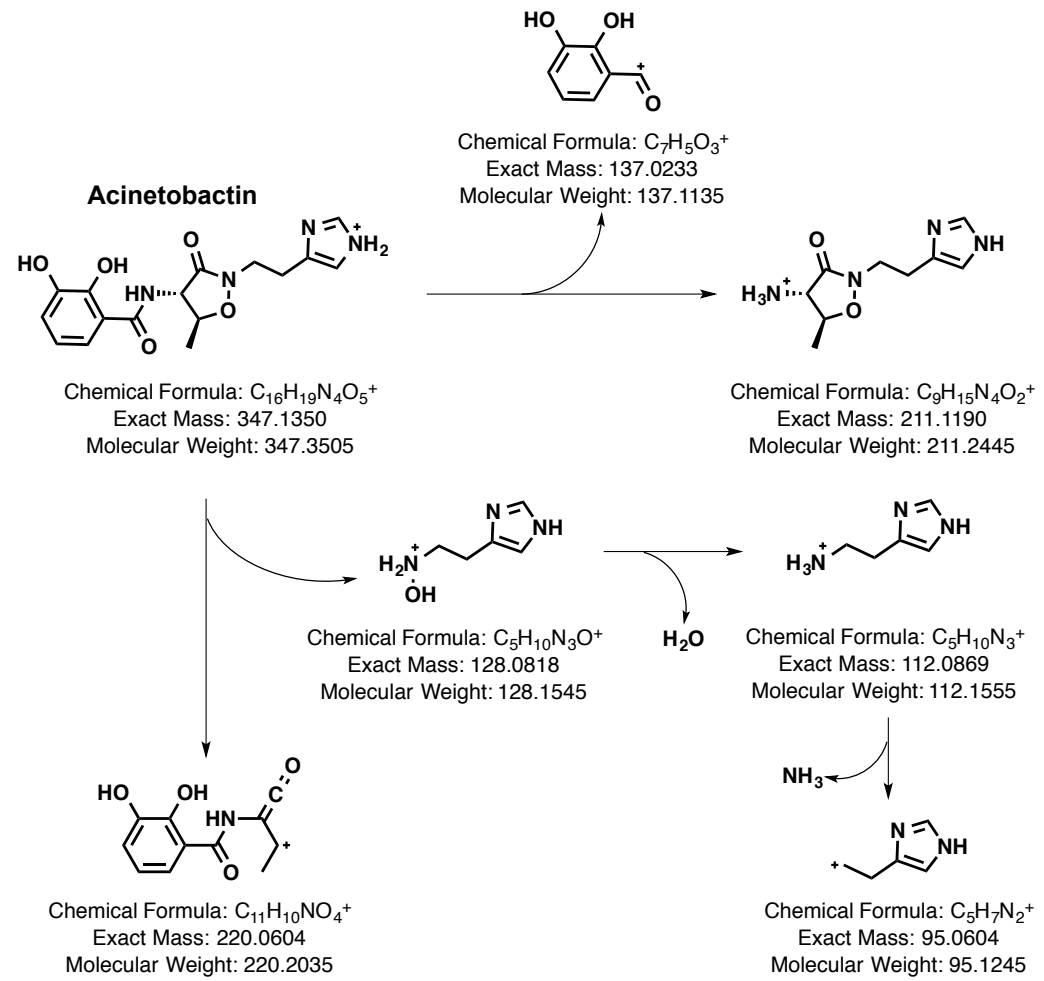

Scheme S3. Proposed fragmentation of acinetobactin. All fragment masses were identified in the high-resolution MS-MS spectra shown in Figures S14-S16 for natural and synthetic acinetobactin.

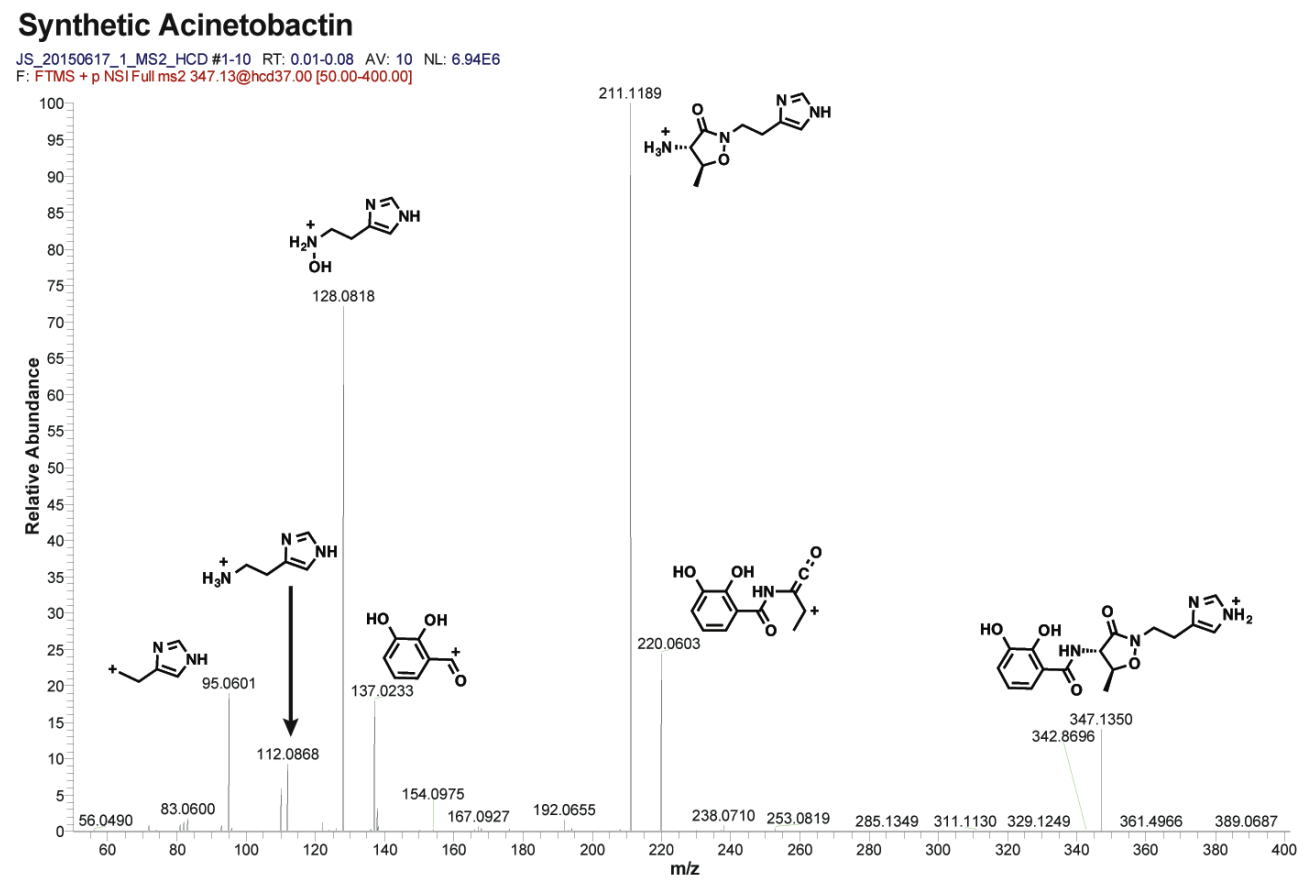

Figure S14. High-resolution MS-MS analysis of synthetic acinetobactin. 


\section{Natural Acinetobactin}

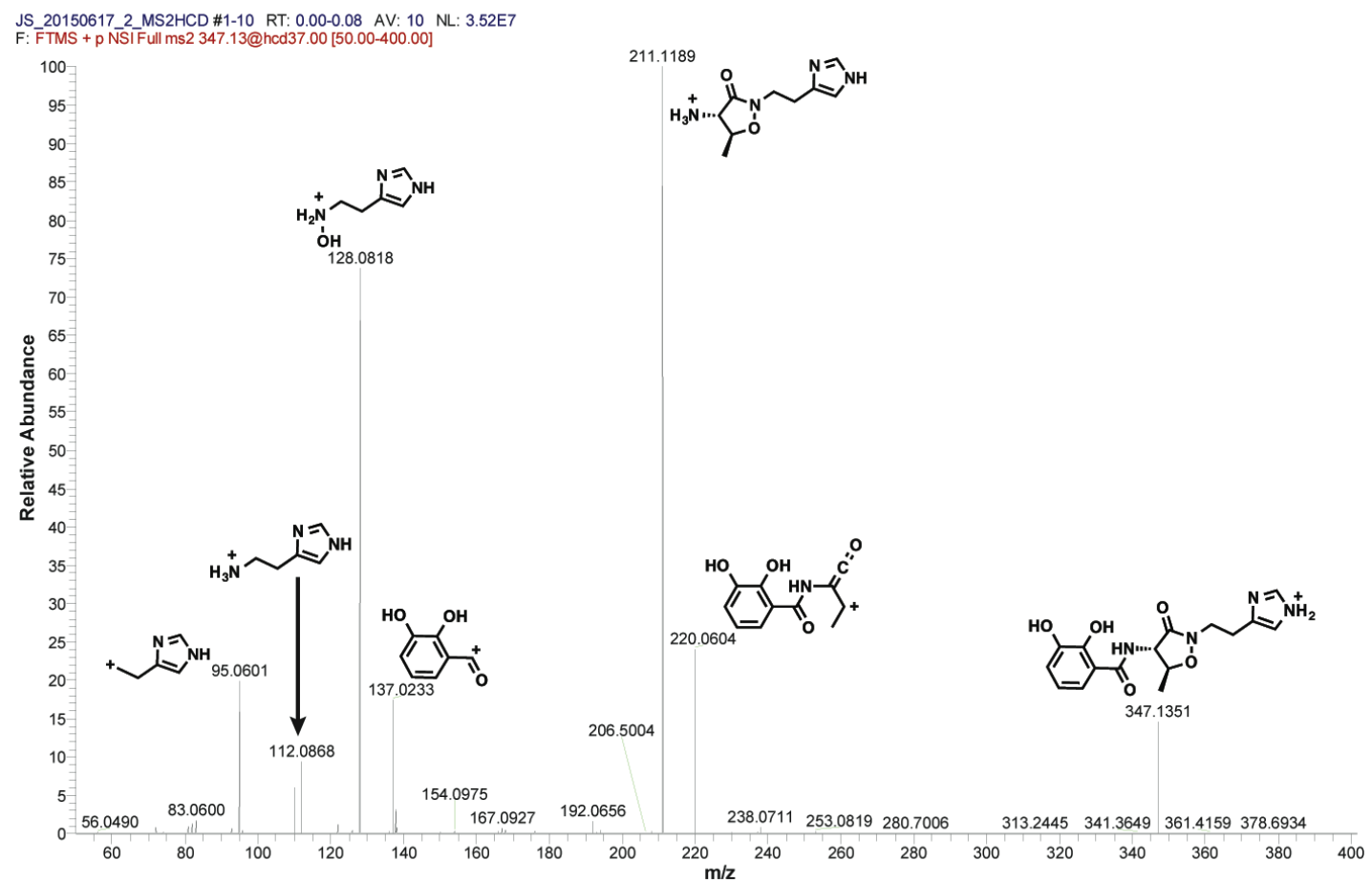

Figure S15. High-resolution MS-MS analysis of natural acinetobactin.

Mixed Natural and Synthetic Acinetobactin

JS_20150617_3_MS2HCD \#1-10 RT: 0.00-0.08 AV: 10 NL: 7.87E7

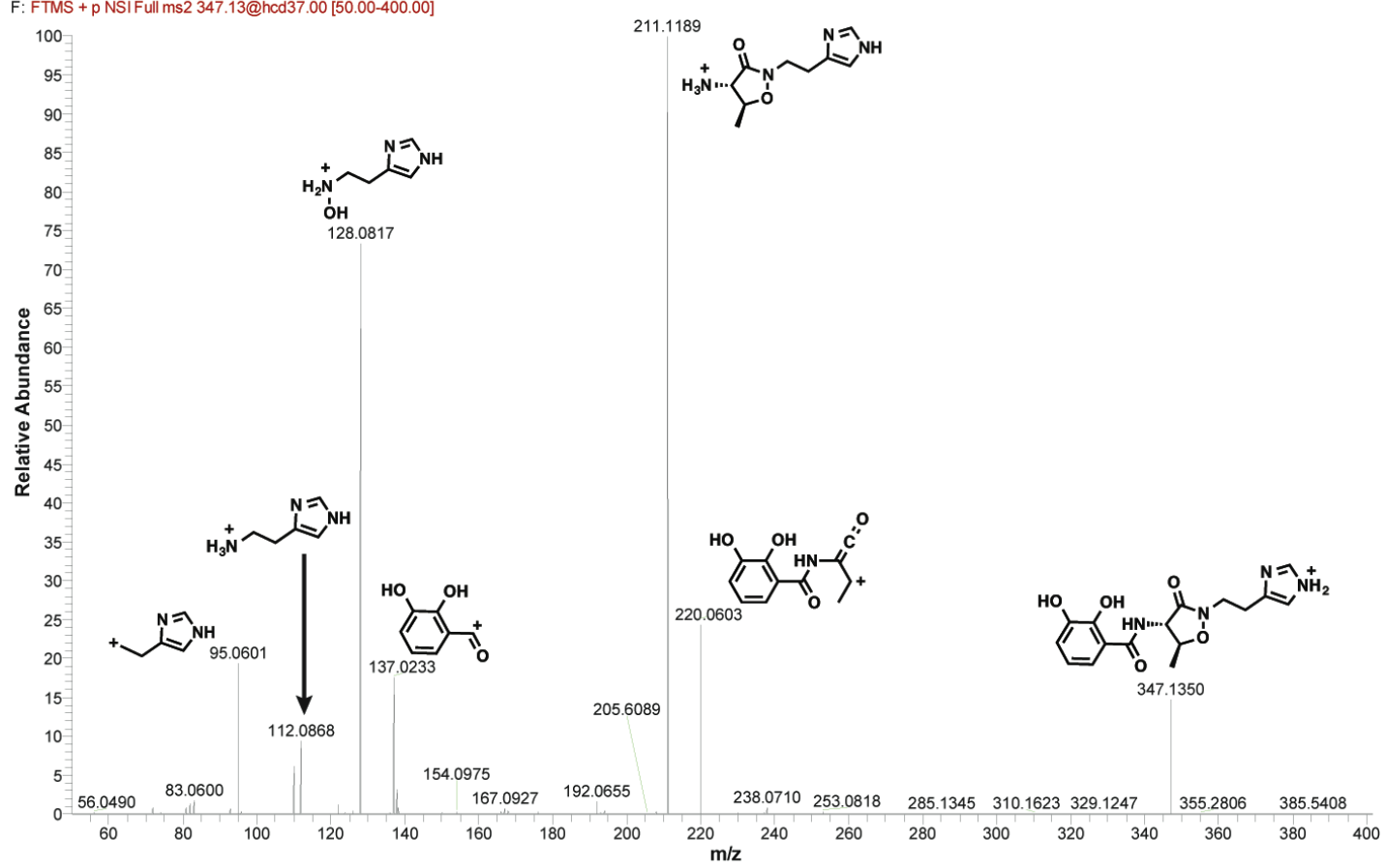

Figure S16. High-resolution MS-MS analysis of mixed synthetic and natural acinetobactin. 


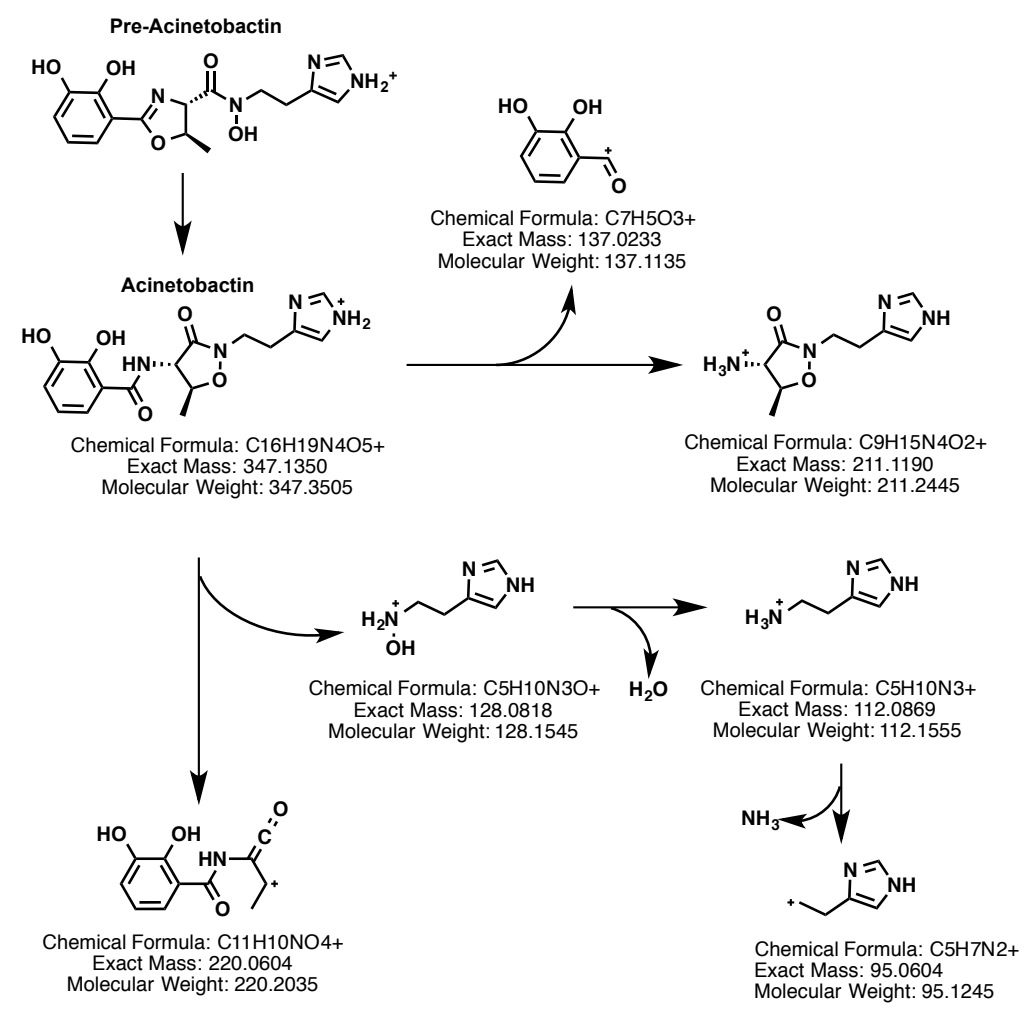

Scheme S4. Proposed fragmentation of pre-acinetobactin. All fragment masses were identified in the high-resolution MS-MS spectra shown in Figure S17. The heat from the ionization process most likely rapidly isomerizes pre-acinetobactin before it can form any unique fragments.

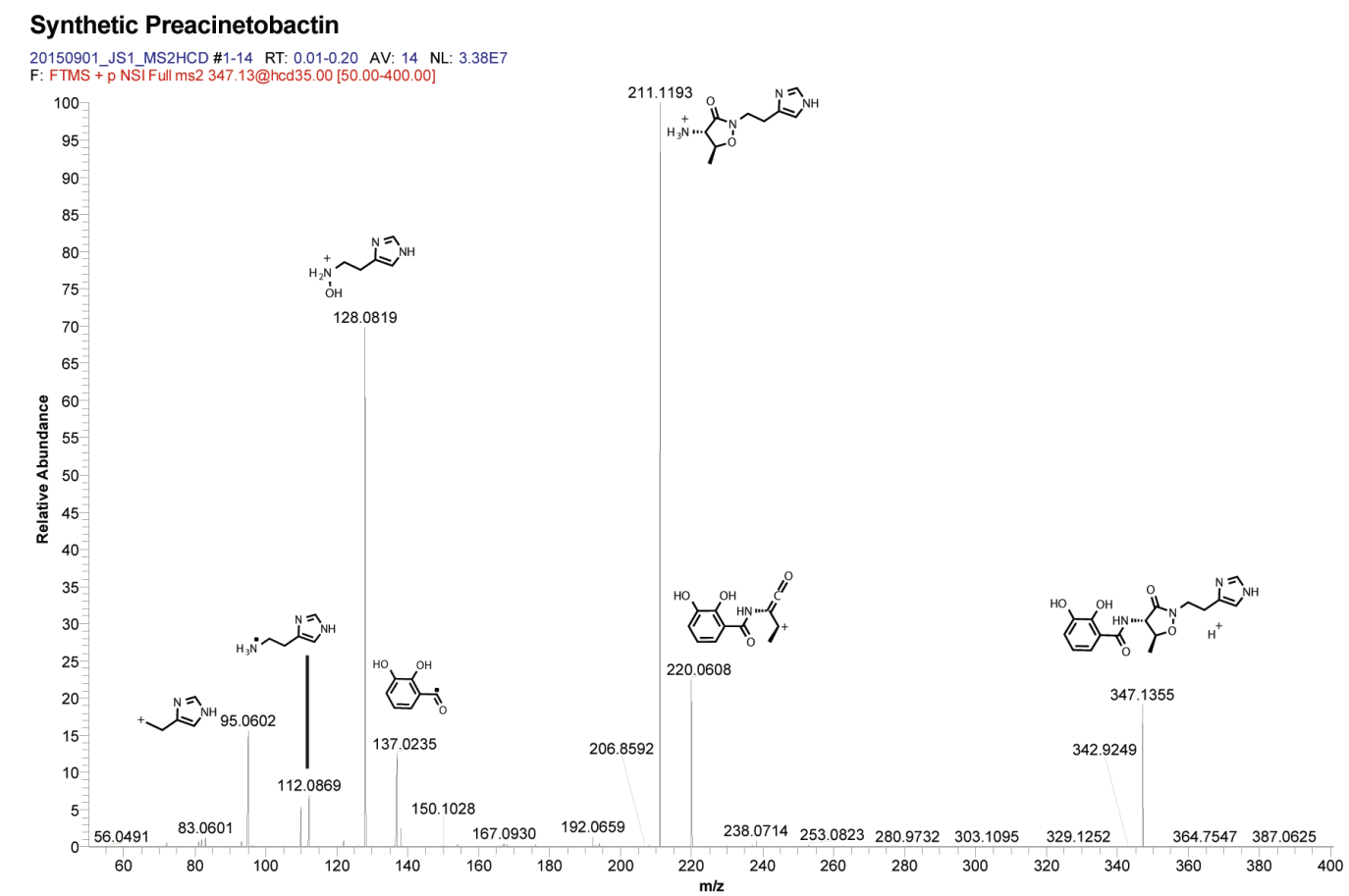

Figure S17. High-resolution MS-MS analysis of synthetic pre-acinetobactin. 


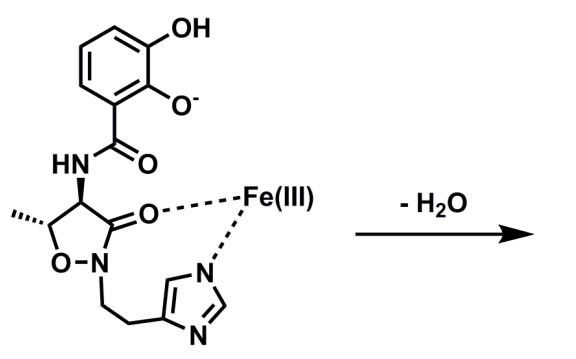

Chemical Formula: $\mathrm{C}_{16} \mathrm{H}_{16} \mathrm{FeN}_{4} \mathrm{O}_{5}{ }^{+}$ Exact Mass: 400.0476

Molecular Weight: 400.1725

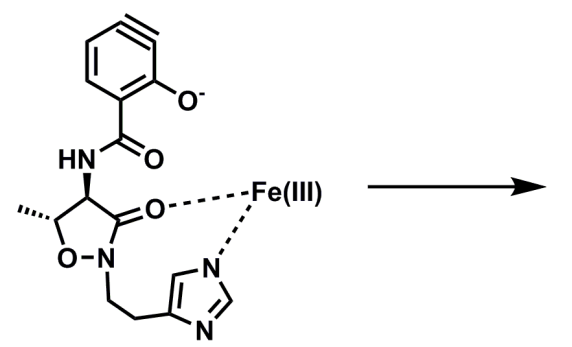

Chemical Formula: $\mathrm{C}_{16} \mathrm{H}_{14} \mathrm{FeN}_{4} \mathrm{O}_{4}{ }^{+}$

Exact Mass: 382.0370

Molecular Weight: 382.1575

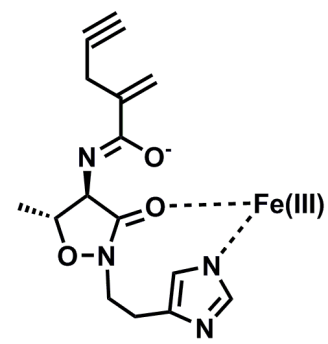

Chemical Formula: $\mathrm{C}_{15} \mathrm{H}_{16} \mathrm{FeN}_{4} \mathrm{O}_{3}{ }^{+}$ Exact Mass: 356.0577

Molecular Weight: 356.1635

Scheme S5. Proposed fragmentation of acinetobactin-Fe(III). All fragment masses were identified in the high-resolution MS-MS spectra shown in Figure S18.

\section{Acinetobactin-Fe(iii)}

JS_20150808_2_MS2_CID_400\#1-14 RT: 0.00-0.20 AV: 14 NL: 4.82E5

F: FTMS + p NSI Full ms2 400.05@cid30.00 [110.00-500.00]

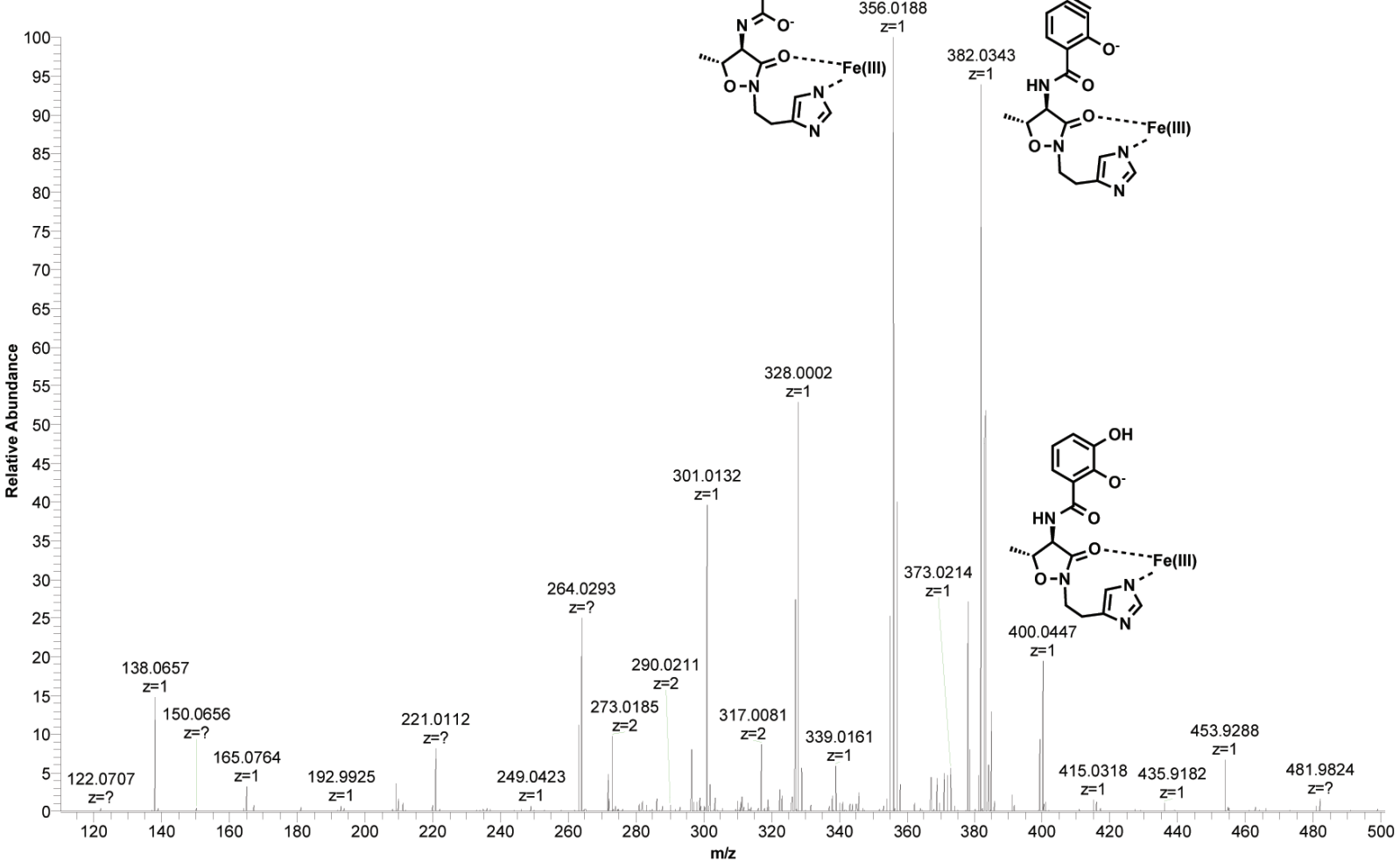

Figure S18. High-resolution MS-MS analysis of acinetobactin-Fe(III) complex. 


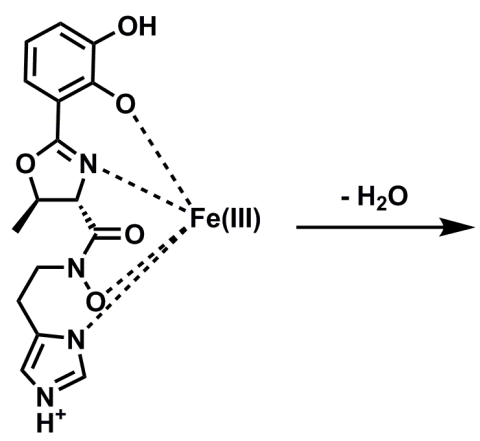

Chemical Formula: $\mathrm{C}_{16} \mathrm{H}_{16} \mathrm{FeN}_{4} \mathrm{O}_{5}{ }^{+}$

Exact Mass: $\mathbf{4 0 0 . 0 4 6 5}$

Molecular Weight: 400.1715

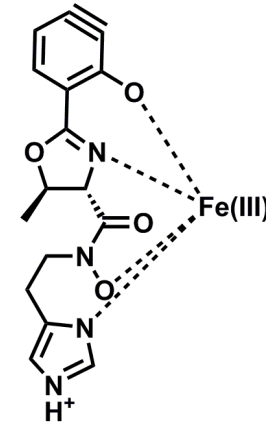

Chemical Formula: $\mathrm{C}_{16} \mathrm{H}_{14} \mathrm{FeN}_{4} \mathrm{O}_{4}{ }^{+}$

Exact Mass: 382.0359

Molecular Weight: 382.1565

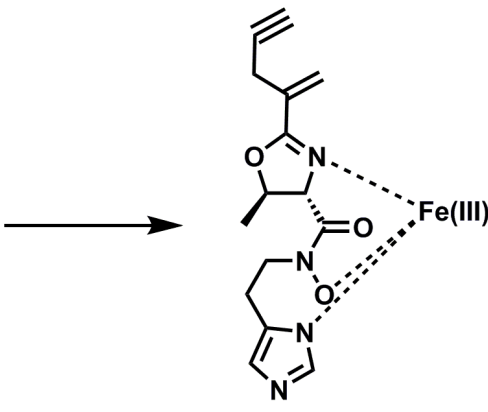

Chemical Formula: $\mathrm{C}_{15} \mathrm{H}_{16} \mathrm{FeN}_{4} \mathrm{O}_{3}{ }^{+}$

Exact Mass: 356.0572

Molecular Weight: $\mathbf{3 5 6 . 1 6 3 0}$

Scheme S6. Proposed fragmentation of pre-acinetobactin-Fe(III). All fragment masses were identified in the high-resolution MS-MS spectra shown in Figures S19.

\section{Pre-acinetobactin-Fe(iii)}

JS_20150808_1_MS2_CID_400\#1-14 RT: 0.00-0.19 AV: 14 NL: $1.03 E 7$

F: FTMS + p NSI Full ms2 400.05@cid30.00 [110.00-500.00]
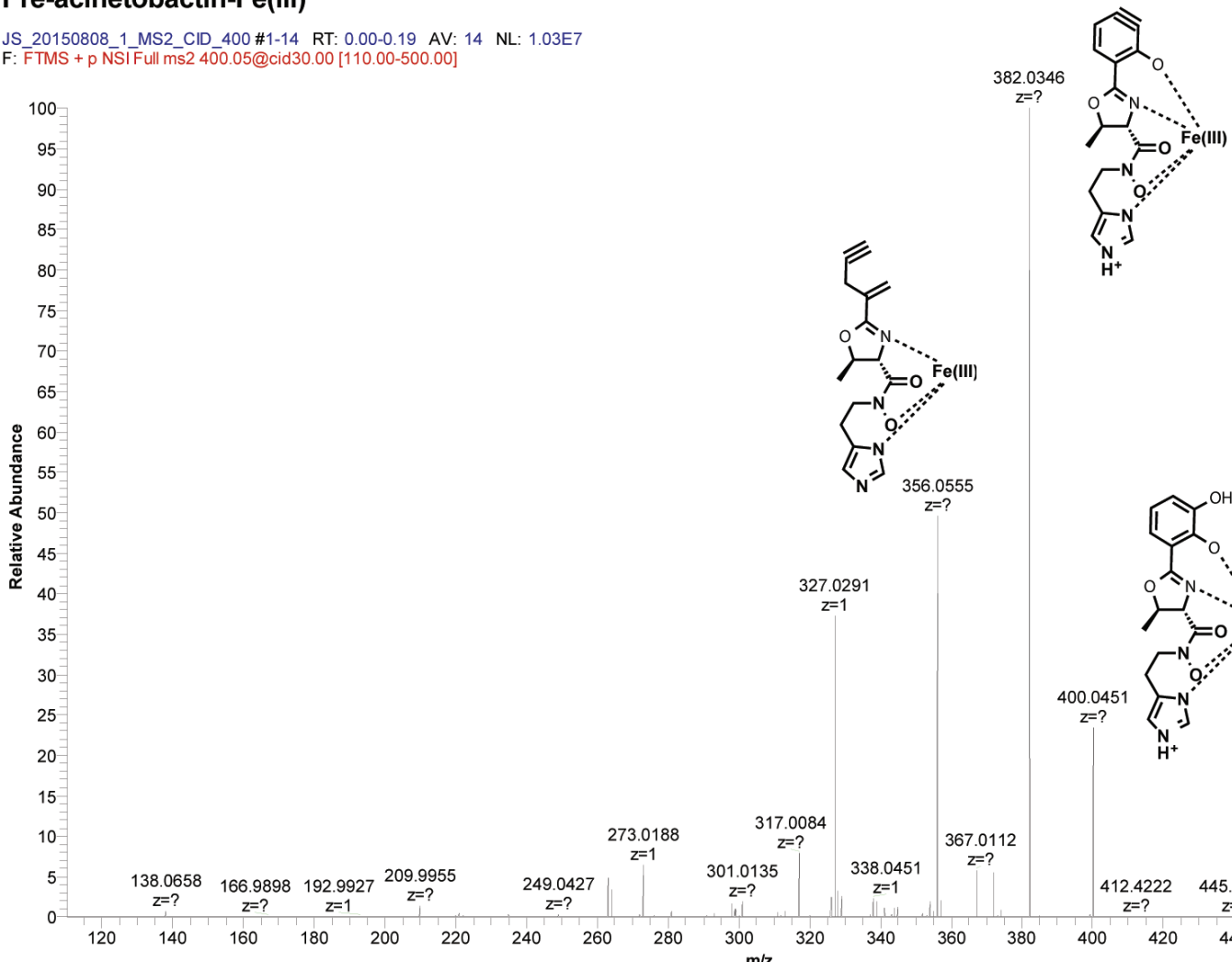

$\begin{array}{llllll}120 & 140 & 160 & 180 & 200 & 220\end{array}$

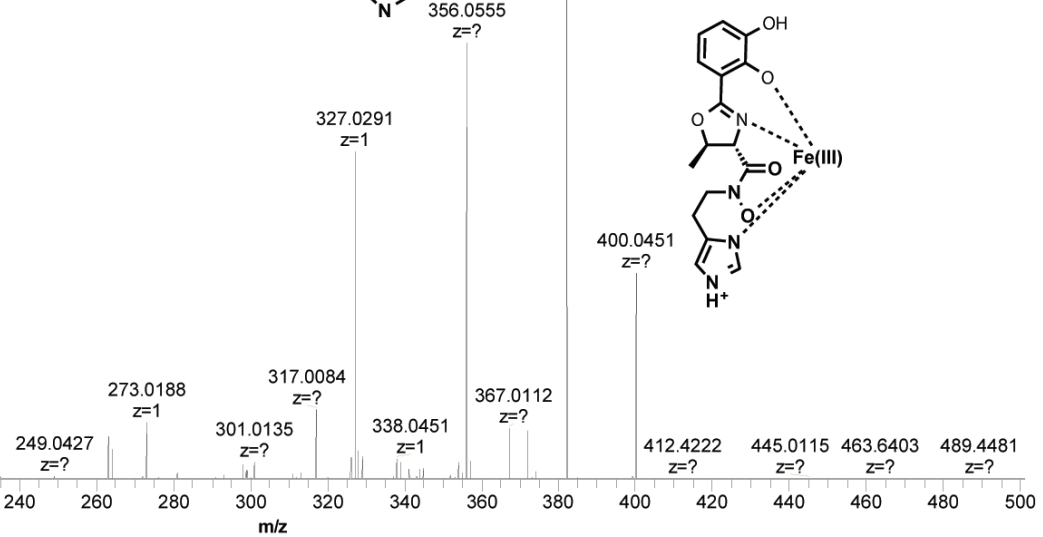

Figure S19. High-resolution MS-MS analysis of pre-acinetobactin-Fe(III) complex. 


\section{Titrations of Apo-Siderophores with Tris(acetylacetonato) Iron(III)}

Procedure: Stock solutions of apo-pre-acinetobactin 1a $(14.52 \mathrm{mM})$ and apo-acinetobactin $1 \mathbf{b}$ $(12.83 \mathrm{mM})$ were prepared in $\mathrm{D}_{2} \mathrm{O}$ and quantified with an acetonitrile internal standard. A stock solution of tris(acetylacetonato) iron(III) $(12.74 \mathrm{mM})$ was prepared in methanol by use of an analytical balance and volumetric glassware. Stock siderophore solutions were diluted into 10 mM HEPES (pH 7.4) (20 $\mu \mathrm{L}$ stock into $980 \mu \mathrm{L}$ buffer) and the sample was scanned. Then $5 \mu \mathrm{L}$ of tris(acetylacetonato) iron(III) stock was added and the sample was scanned. The solutions quickly went from colorless to colored (magenta for pre-acinetobactin and purple for acinetobactin). Tris(acetylacetonato) iron(III) stock was added $1 \mu \mathrm{L}$ at a time and a scan was taken after each addition. For pre-acinetobactin titration, all solution transfers and scans were taken as quickly as possible to avoid isomerization. The titration curves are based off of absorbance at $650 \mathrm{~nm}$ to avoid interference from excess tris(acetylacetonato) iron(III), which absorbs at the peaks for 1a-Fe(III) and $\mathbf{1 b}-\mathbf{F e}($ III) $(515 \mathrm{~nm}$ and $570 \mathrm{~nm}$, respectively) but not at $650 \mathrm{~nm}$.

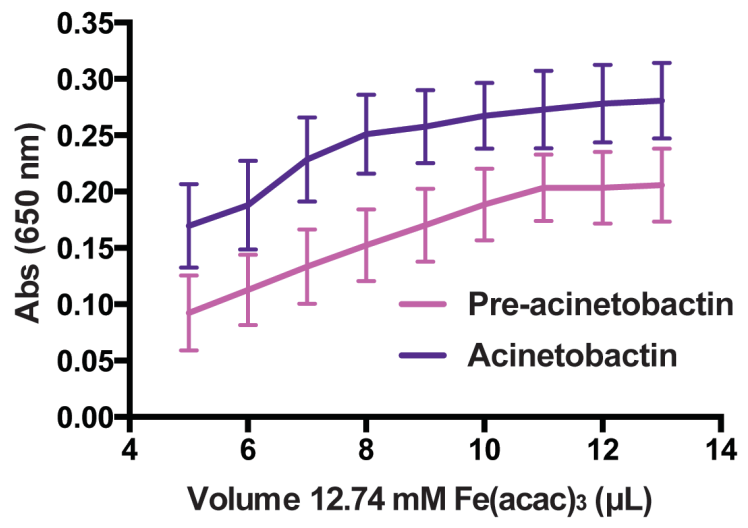

\section{Extinction Coefficients}

Apo-pre-acinetobactin (315 nm): $3147 \mathrm{M}^{-1} \mathrm{~cm}^{-1}$

Apo-acinetobactin (330): $3176 \mathrm{M}^{-1} \mathrm{~cm}^{-1}$

Pre-acinetobactin-Fe(III) (515 nm): $2829 \mathrm{M}^{-1} \mathrm{~cm}^{-1}$

Pre-acinetobactin-Fe(III) (650 nm): $1269 \mathrm{M}^{-1} \mathrm{~cm}^{-1}$

Acinetobactin-Fe(III) $(570 \mathrm{~nm}): 3171 \mathrm{M}^{-1} \mathrm{~cm}^{-1}$

Acinetobactin-Fe(III) (650 nm): $2165 \mathrm{M}^{-1} \mathrm{~cm}^{-1}$

Figure S20. Titration curves for pre-acinetobactin and acinetobactin by tris(acetylacetonato) iron(III). The endpoint of the titration was considered to be $11 \mathrm{uL}$ for each siderophore. The siderophore:metal ratios at the endpoint for pre-acinetobactin and acinetobactin were calculated to be $2.07: 1$ and $1.84: 1$, respectively. 


\section{NMR Data for Purified Compounds}

Table S2. 2D NMR characterization data of pre-acinetobactin TFA salt in DMSO-d6.

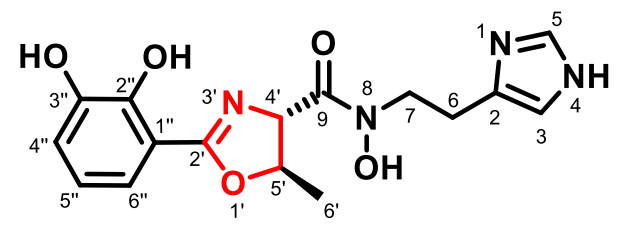

\begin{tabular}{|c|c|c|c|c|c|c|}
\hline Atom & $\begin{array}{l}{ }_{(p p m)}^{13} \\
(p)\end{array}$ & $\begin{array}{l}\operatorname{actin}(1 \mathrm{a}) \\
{ }^{1} \mathrm{H} \quad(\mathbf{p p m}), \\
\text { multiplets in } \mathbf{H z}\end{array}$ & $\begin{array}{l}\text { gCOSY } \\
{ }^{1} \mathrm{H}^{1} \mathrm{H} \\
3 \text { bond }\end{array}$ & $\begin{array}{l}\text { TOCSY } \\
{ }^{1} \mathrm{H}^{1}{ }^{1} \mathrm{H} \\
4-5 \text { bond }\end{array}$ & $\begin{array}{c}\text { HMBC } \\
{ }^{1} \mathrm{H}^{13} \mathrm{C} \\
2-3 \text { bond }\end{array}$ & $\begin{array}{ll}\text { ROESY } & { }^{1} H-{ }^{1} H \\
\text { through } & \text { space, } \\
6 \AA & \end{array}$ \\
\hline 2 & 131.7 & & & & $3,5,6,7$ & \\
\hline 3 & 135.4 & $8.97(\mathrm{~s}, 1 \mathrm{H})$ & & 5 & 2,5 & \\
\hline 5 & 117.8 & $7.43(\mathrm{~s}, 1 \mathrm{H})$ & & 3 & 2,3 & \\
\hline 6 & 23.0 & $\begin{array}{l}3.05-2.90 \\
(\mathrm{~m}, 2 \mathrm{H})\end{array}$ & 7 & 7 & $2,5,7$ & 7 \\
\hline 7 & 47.0 & $\begin{array}{l}4.00-3.72(\mathrm{~m}, \\
2 \mathrm{H})\end{array}$ & 6 & 6 & 2,6 & 6 \\
\hline 9 & 170.9 & & & & $4^{\prime}, 5^{\prime}$ & \\
\hline $2^{\prime}$ & 167.3 & & & & $4^{\prime}, 6^{\prime \prime}$ & \\
\hline $4^{\prime}$ & 71.5 & $\begin{array}{l}5.00(\mathrm{~d}, J=6.3 \\
\mathrm{Hz}, 1 \mathrm{H})\end{array}$ & 5 & & $9,2^{\prime}, 6^{\prime}$ & 6 ' \\
\hline 5 & 80.1 & $\begin{array}{l}4.80(\mathrm{td}, J=6.2 \\
11.9 \mathrm{~Hz}, 1 \mathrm{H})\end{array}$ & $6^{\prime}, 4^{\prime}$ & & 9,2 ' & $6^{\prime}$ \\
\hline $6^{\prime}$ & 21.7 & $\begin{array}{l}1.42(\mathrm{~d}, J=6.3 \\
\mathrm{Hz}, 3 \mathrm{H})\end{array}$ & 5 & $4^{\prime}, 5^{\prime}$ & $4^{\prime}, 5^{\prime}$ & $4^{\prime}, 5^{\prime}$ \\
\hline $\begin{array}{l}1^{\prime}, \\
2^{\prime},\end{array}$ & 150.0 & & & & $4^{\prime \prime}, 6{ }^{\prime}$ & \\
\hline $3^{\prime}$, & 147.0 & & & & $4 ’, 5$, & \\
\hline $4 "$ & 120.8 & $\begin{array}{l}6.96(\mathrm{dd}, J=1.6 \\
7.8 \mathrm{~Hz}, 1 \mathrm{H})\end{array}$ & 5, & & $1 ', 33^{\prime \prime}, 6^{\prime \prime}$ & \\
\hline 5, & 120.0 & $\begin{array}{l}6.74-6.70(\mathrm{~m}, 1 \\
\mathrm{H})\end{array}$ & $4^{\prime \prime}, 6 "$ & & $3{ }^{\prime \prime}$ & \\
\hline $6 "$ & 119.2 & $\begin{array}{l}7.04(\mathrm{dd}, J=1.6, \\
7.8 \mathrm{~Hz}, 1 \mathrm{H})\end{array}$ & 5, & & $1 ", 4$, & \\
\hline
\end{tabular}




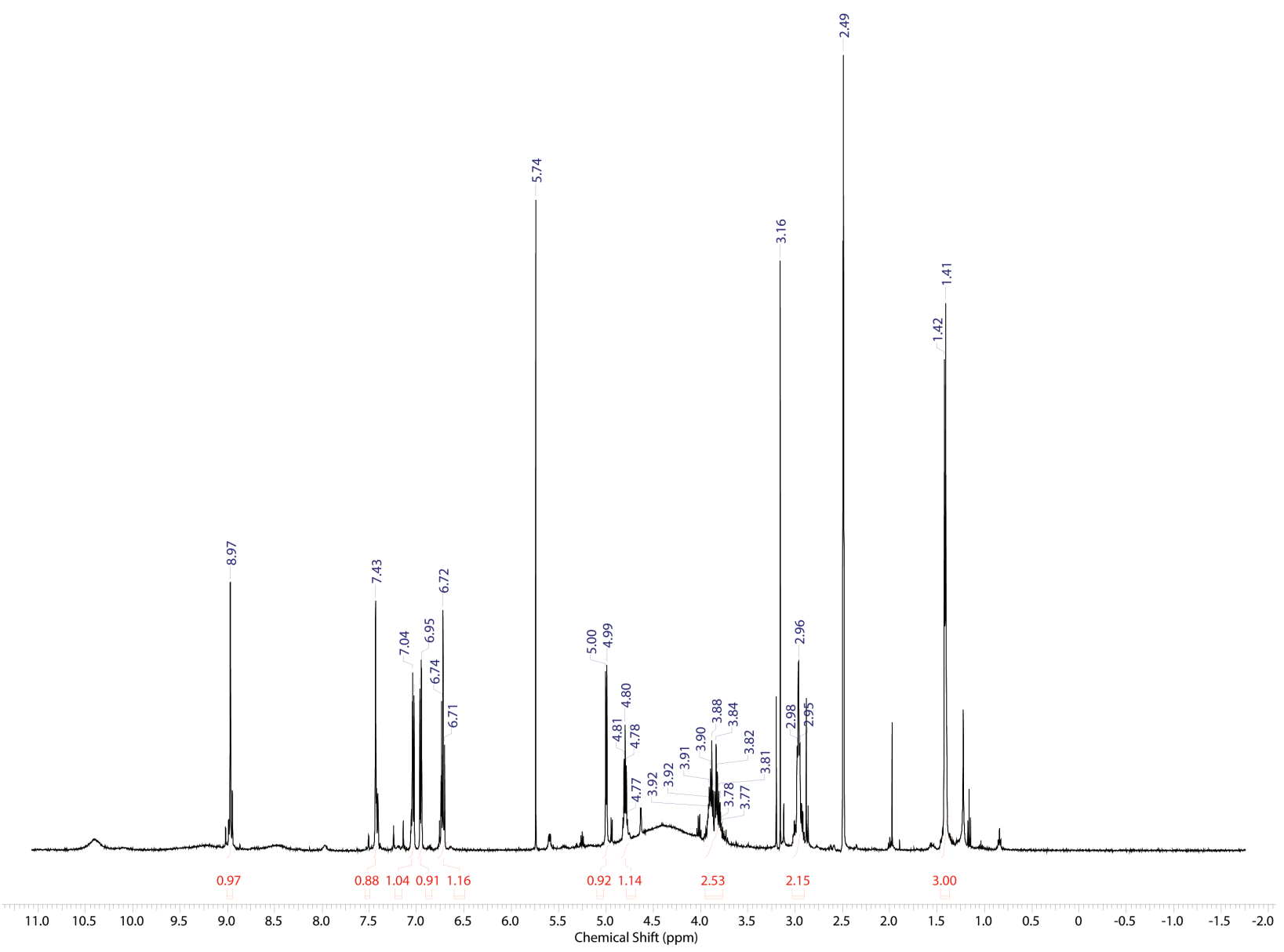

Figure S21. ${ }^{1} \mathrm{H}-\mathrm{NMR}$ spectrum $(500 \mathrm{MHz})$ of pre-acinetobactin TFA salt in DMSO-d6. Signals are assigned in Table $\mathbf{S 2}$. 


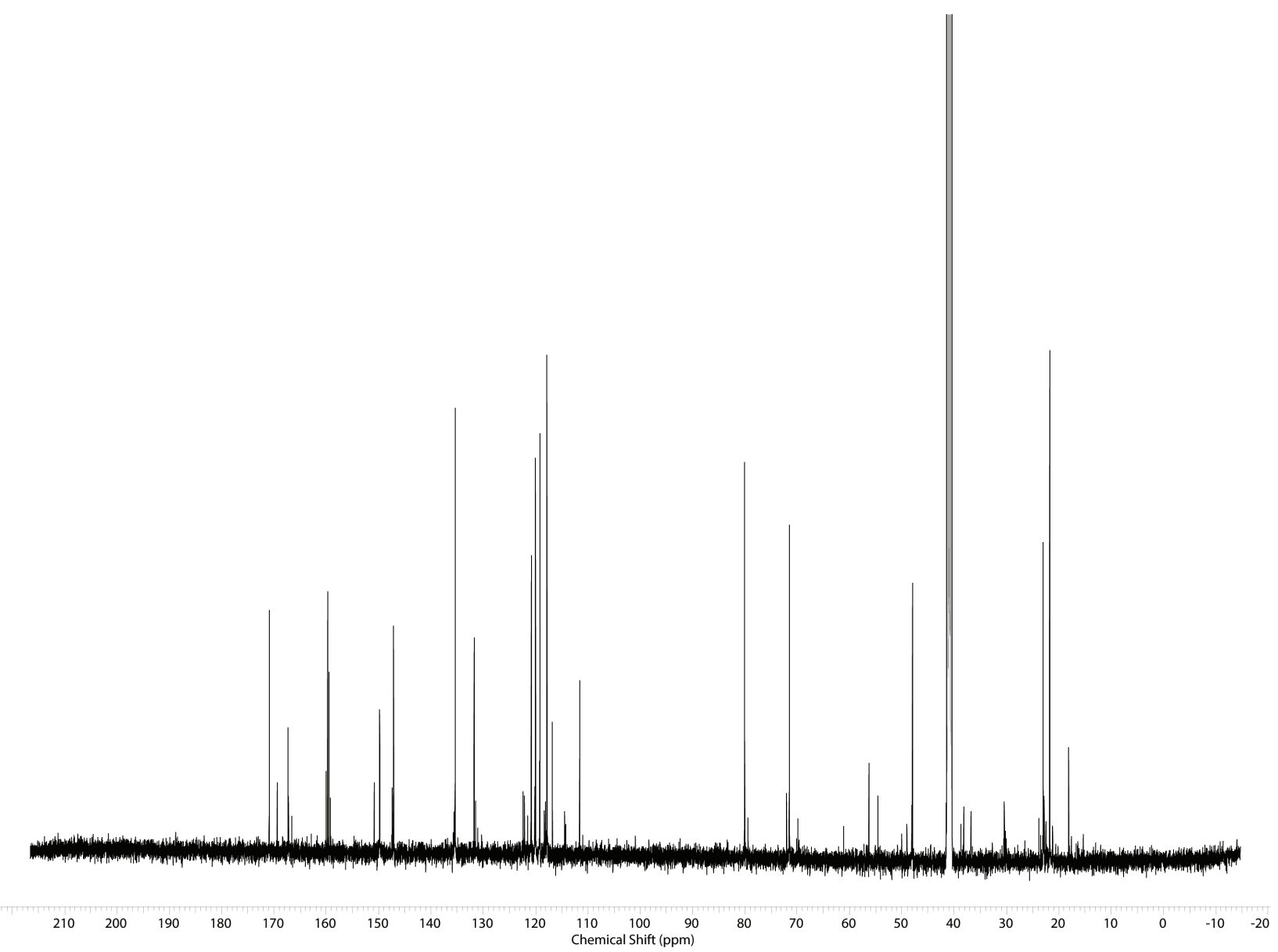

Figure S22. ${ }^{13} \mathrm{C}$-NMR spectrum $(500 \mathrm{MHz})$ of pre-acinetobactin TFA salt in DMSO-d6. Signals are assigned in Table $\mathbf{S 2}$. 


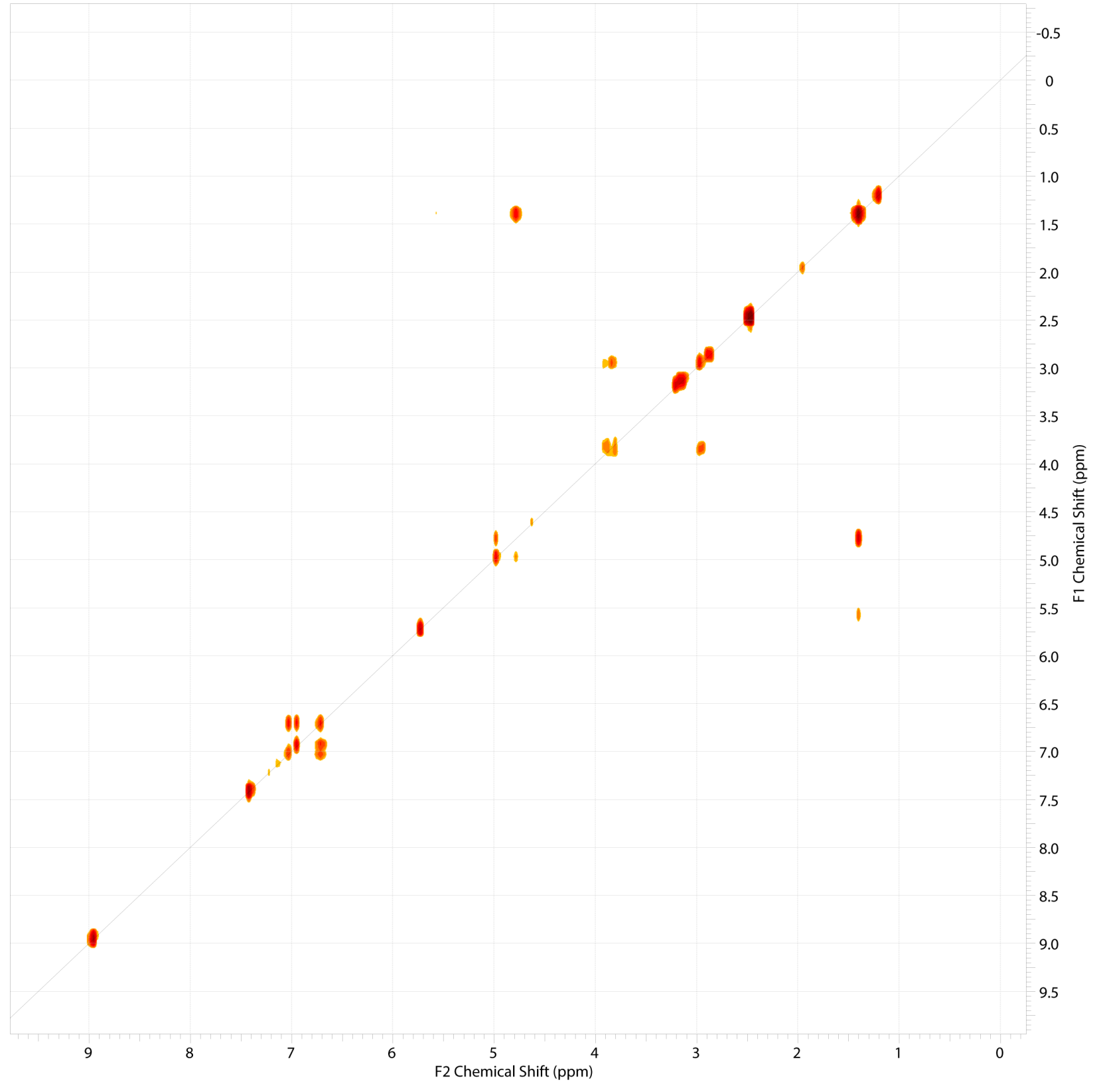

Figure S23. gCOSY spectrum $(500 \mathrm{MHz})$ of pre-acinetobactin TFA salt in DMSO-d6. Correlations are listed in Table S2. 


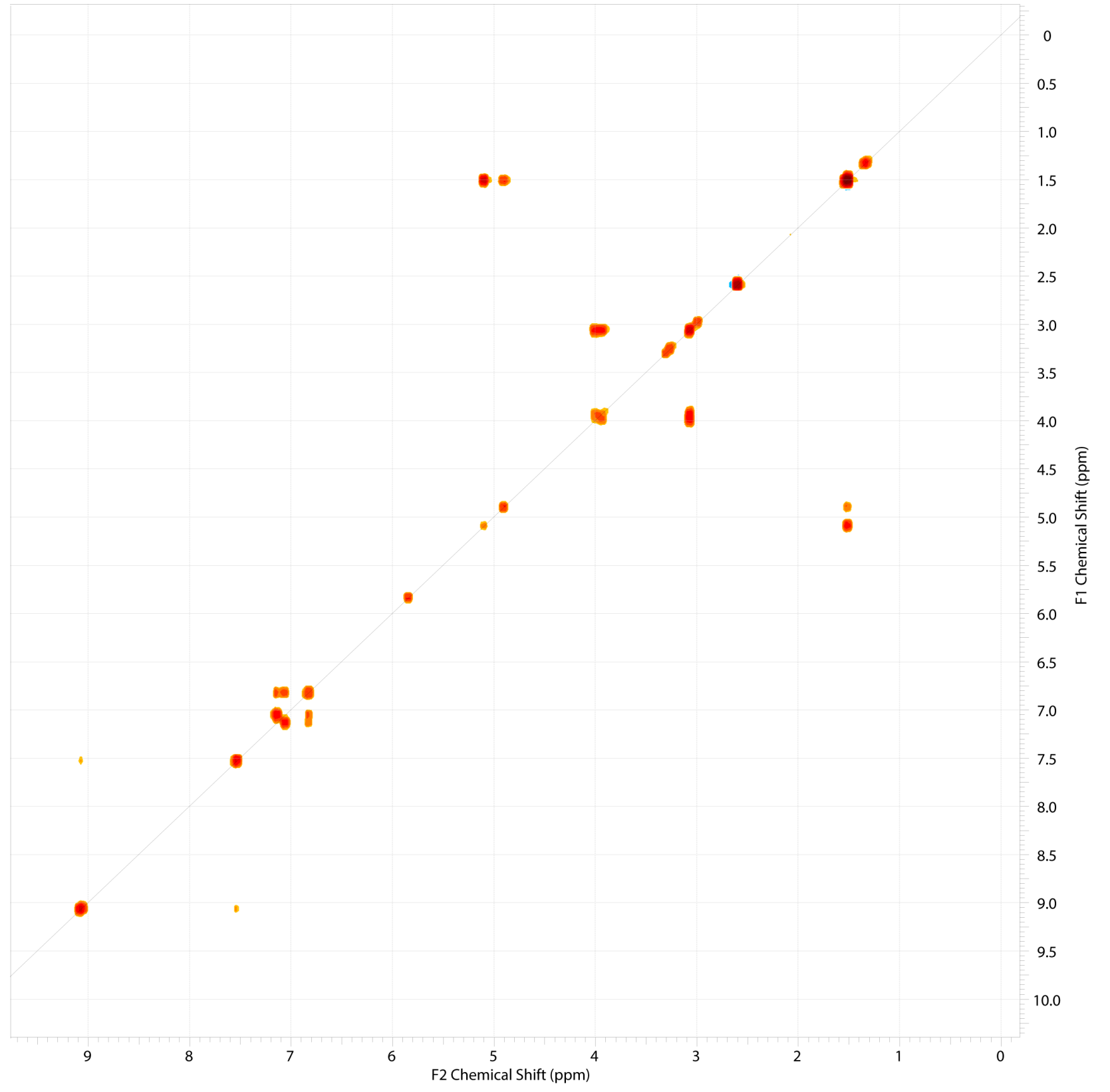

Figure S24. TOCSY spectrum $(500 \mathrm{MHz})$ of pre-acinetobactin TFA salt in DMSO-d6. Correlations are listed in Table S2. 


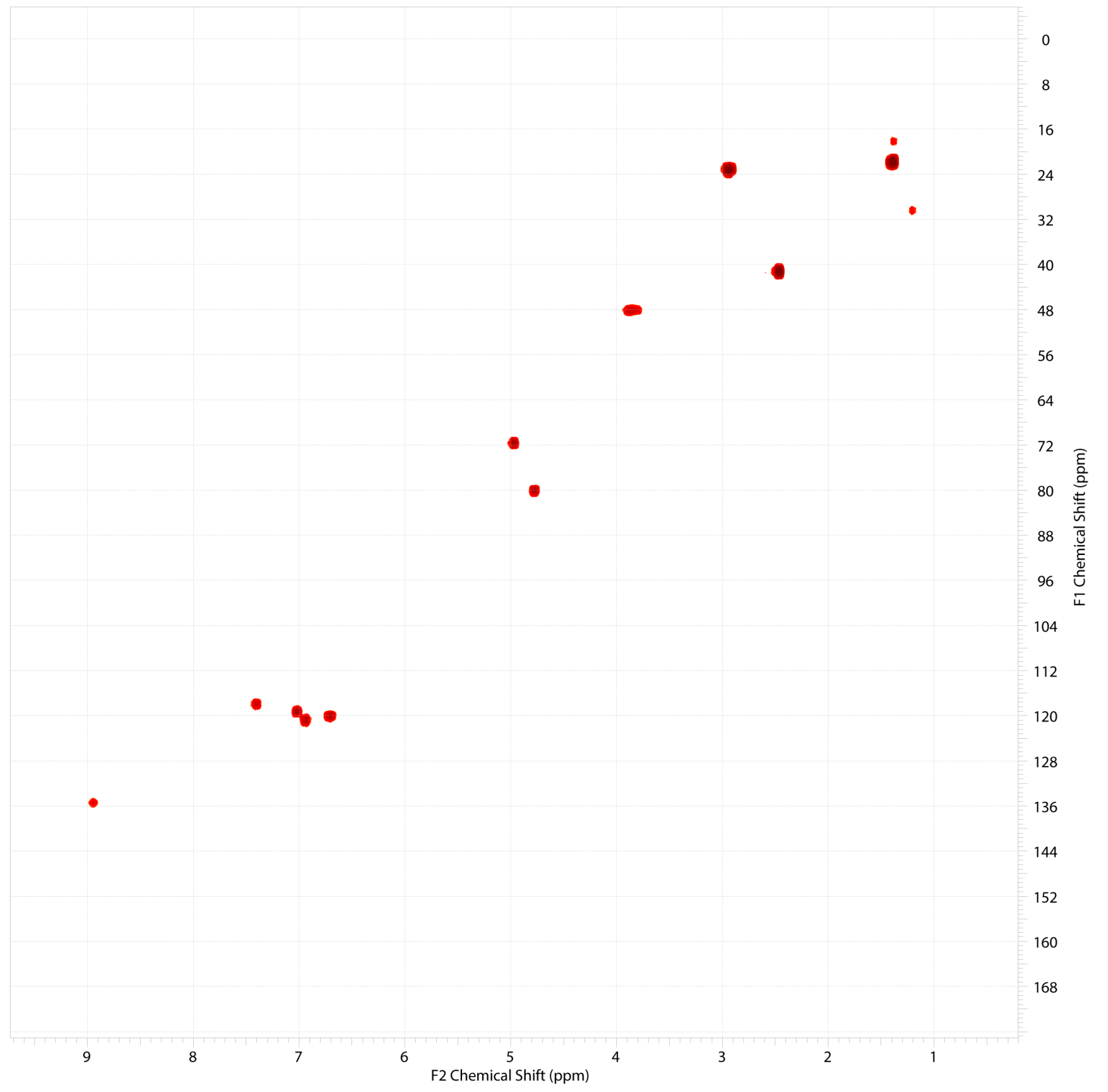

Figure S25. gHSQC spectrum $(500 \mathrm{MHz})$ of pre-acinetobactin TFA salt in DMSO-d6. Correlations are listed in Table S2. 


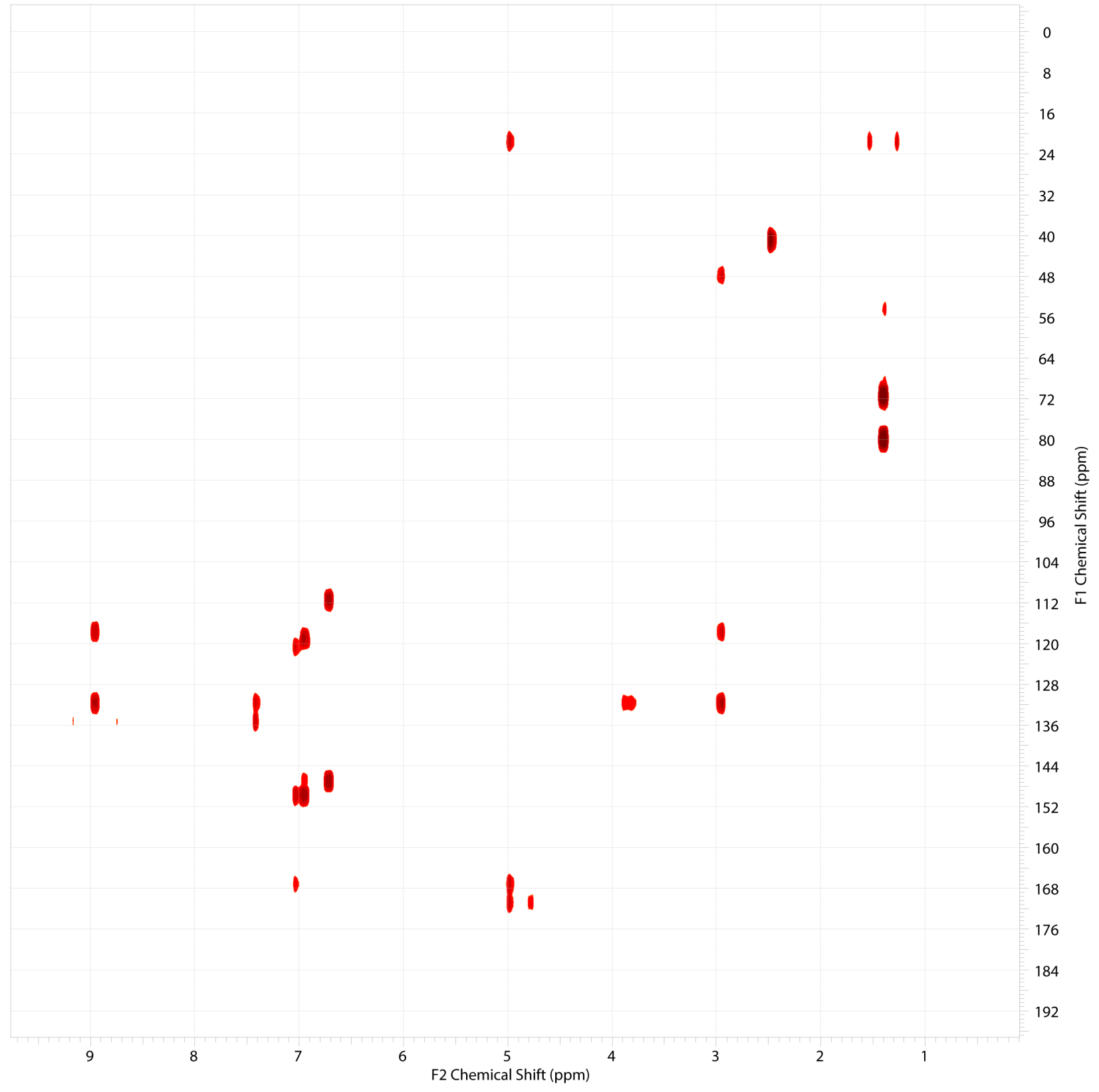

Figure S26. HMBC spectrum $(500 \mathrm{MHz})$ of pre-acinetobactin TFA salt in DMSO-d6. Correlations are listed in Table S2. 


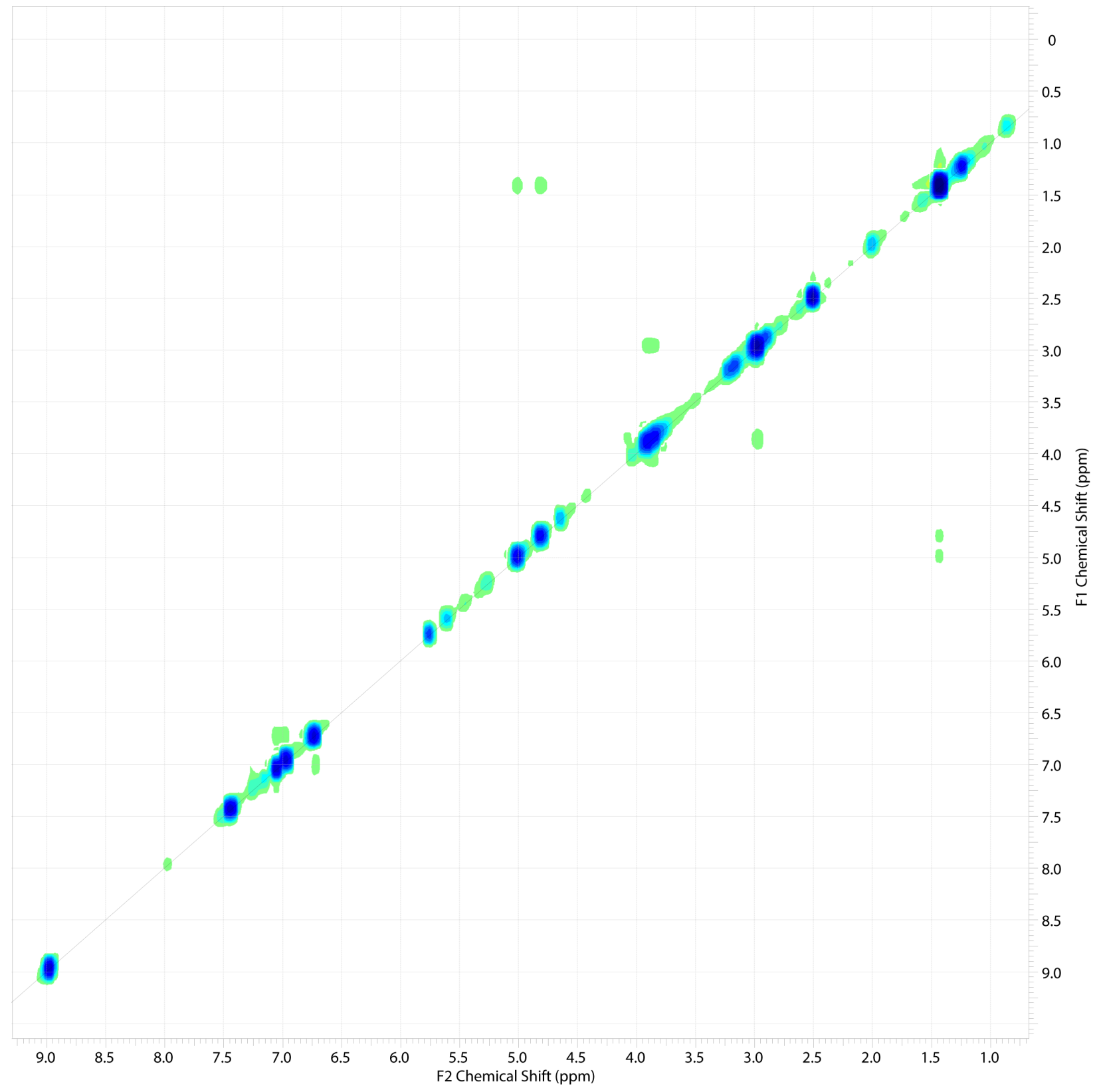

Figure S27. ROESY spectrum $(500 \mathrm{MHz})$ of pre-acinetobactin TFA salt in DMSO-d6. Correlations are listed in Table S2. 
Table S3. 2D NMR characterization data of synthetic acinetobactin TFA salt in DMSO-d6.

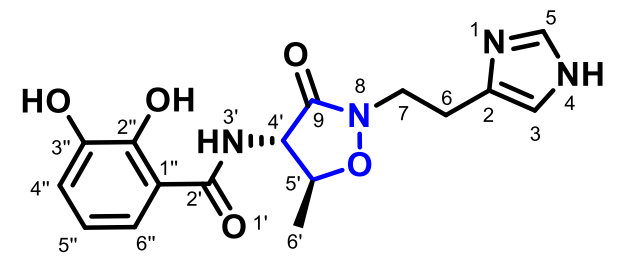

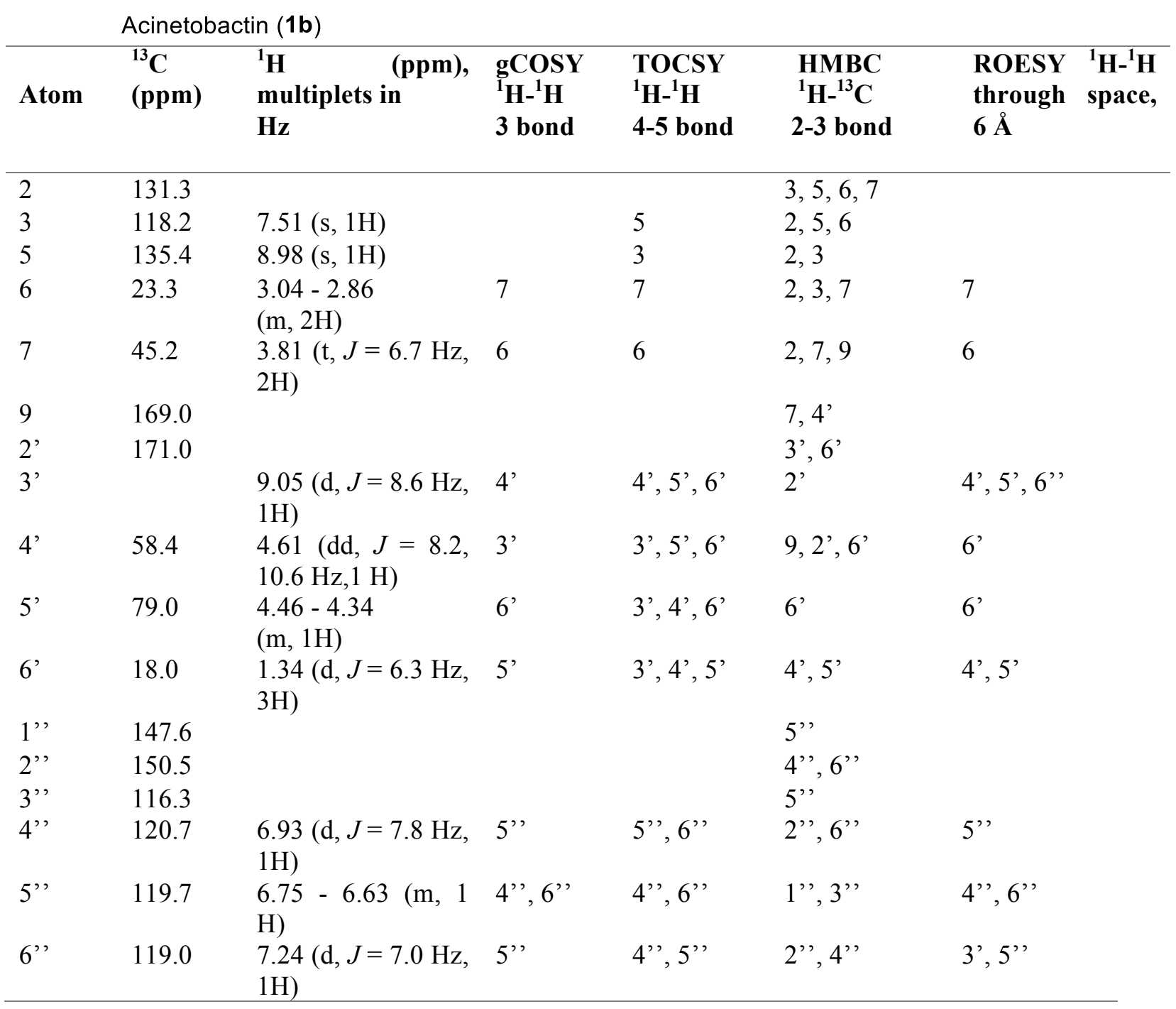



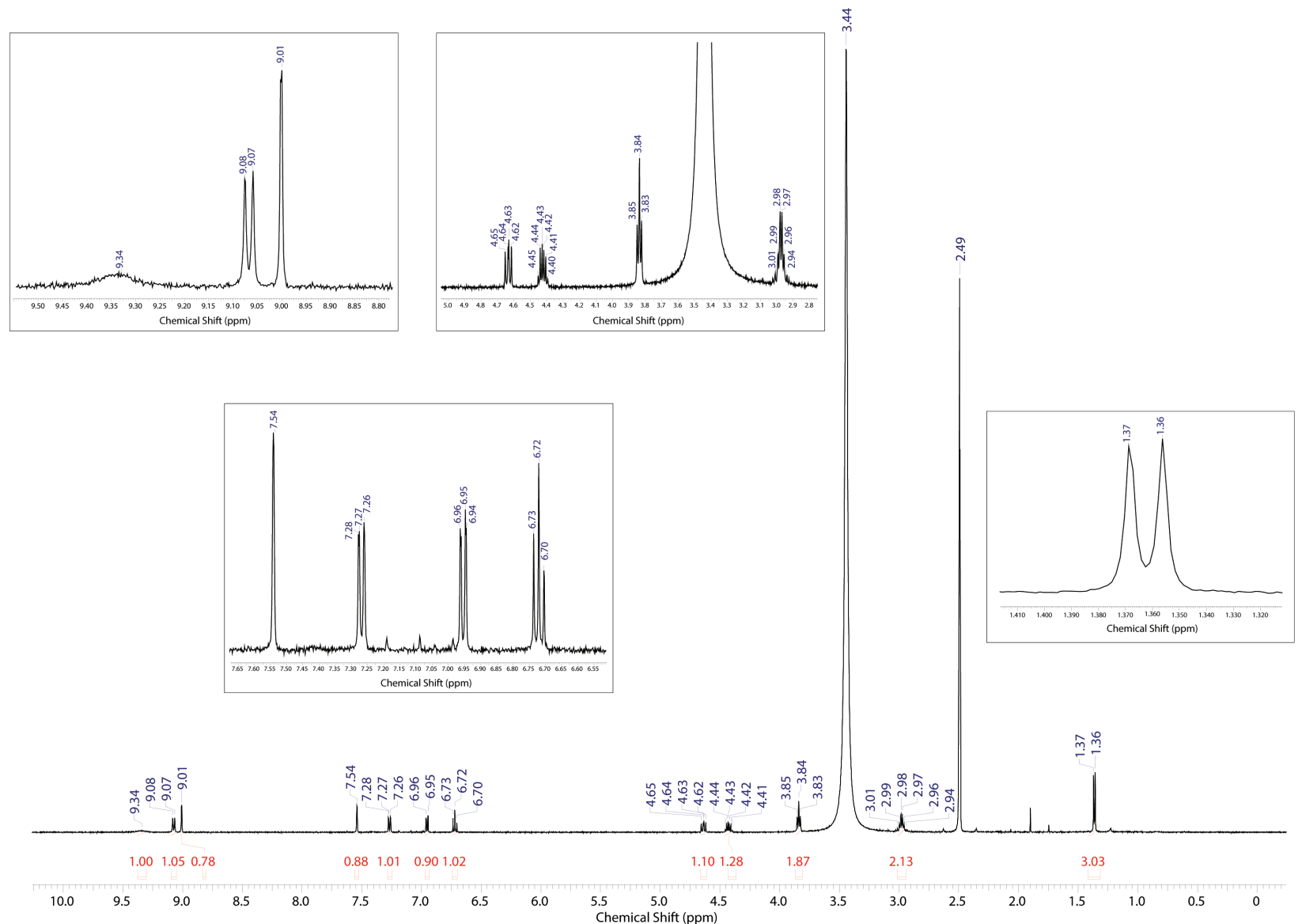

Figure S28. ${ }^{1} \mathrm{H}-\mathrm{NMR}$ spectrum $(500 \mathrm{MHz})$ of synthetic acinetobactin TFA salt in DMSO-d6. Signals are assigned in Table S3. 


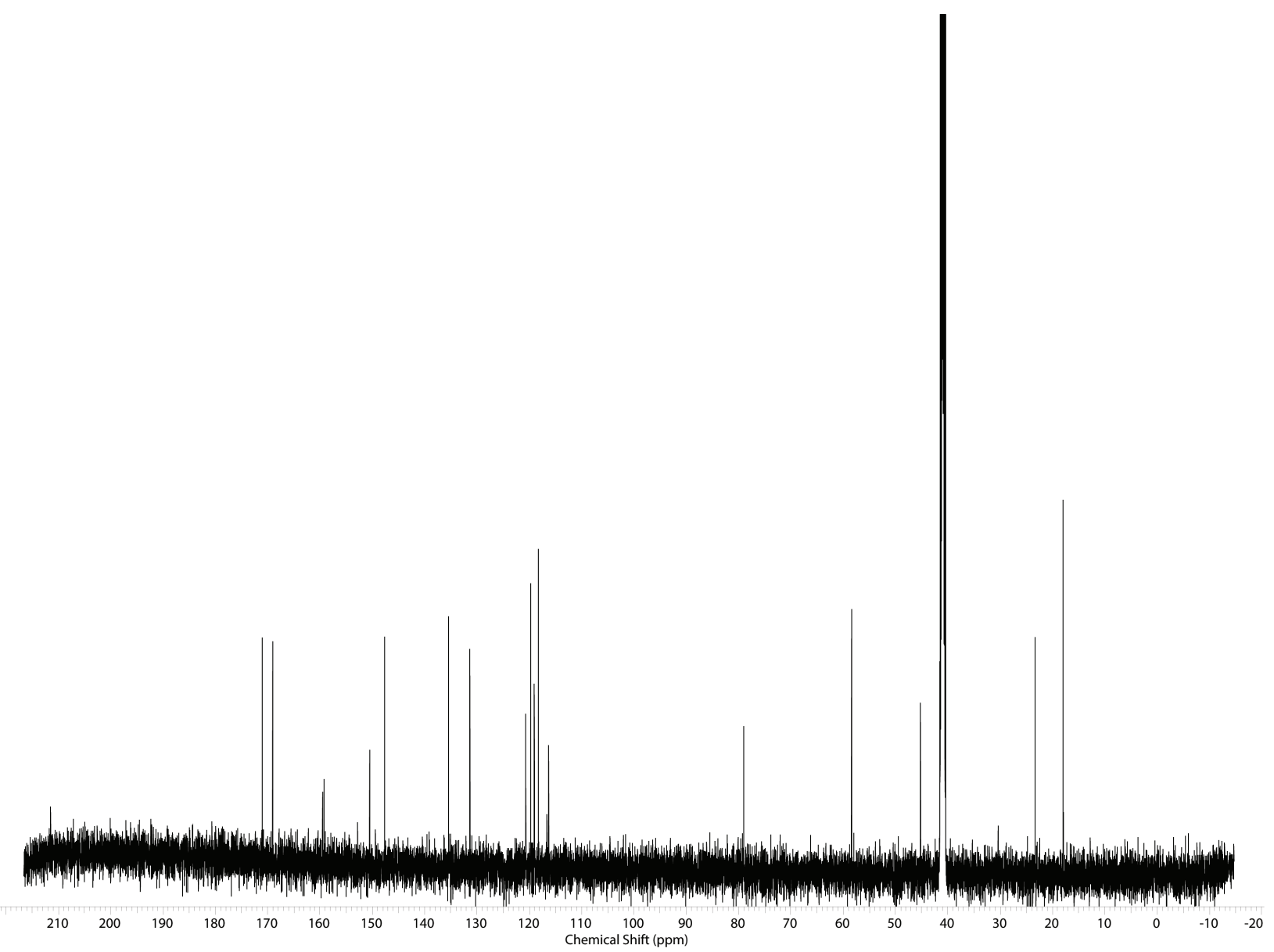

Figure S29. ${ }^{13} \mathrm{C}-\mathrm{NMR}$ spectrum $(500 \mathrm{MHz})$ of synthetic acinetobactin TFA salt in DMSO-d6. Signals are assigned in Table S3. 


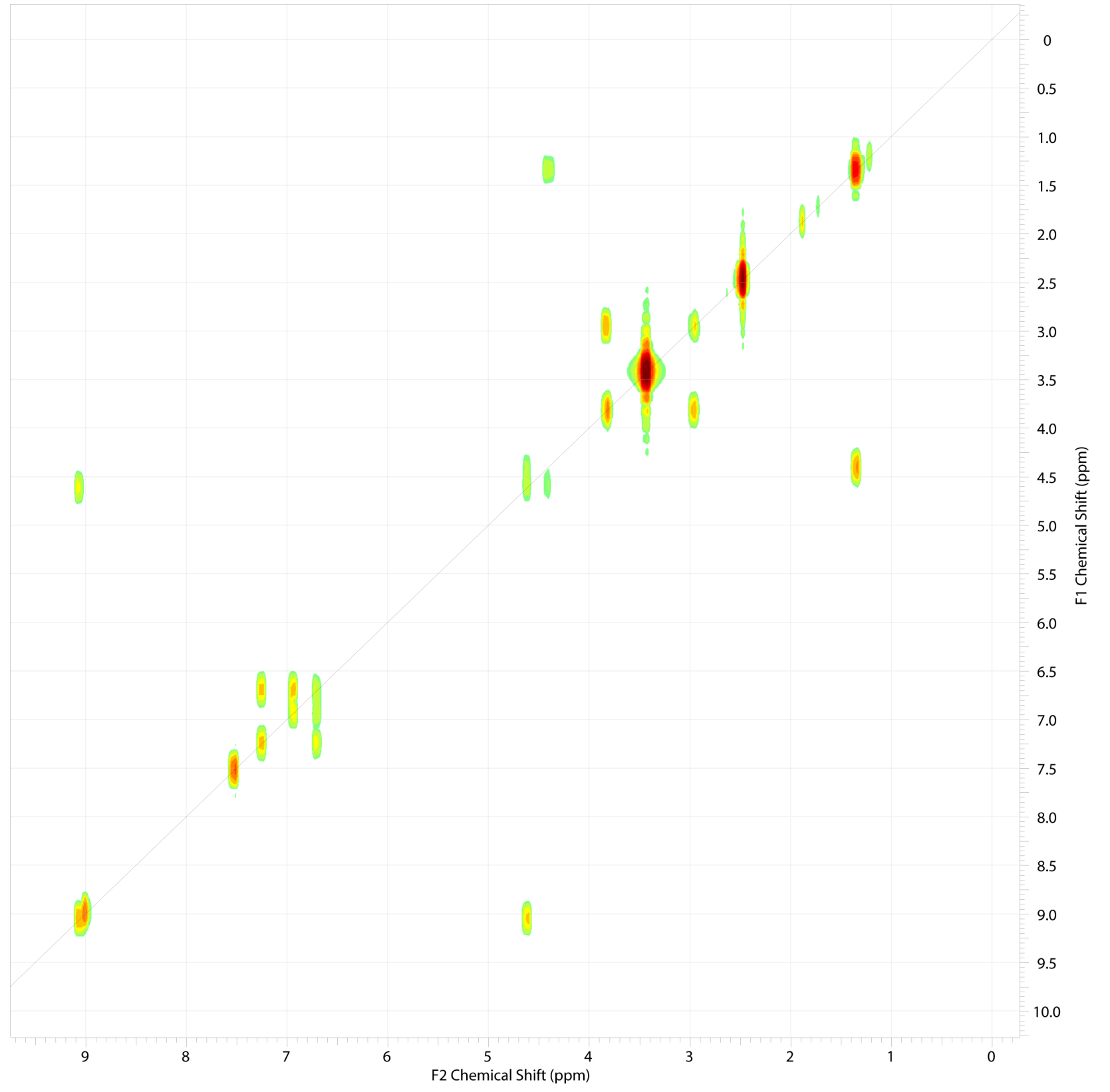

Figure S30. gCOSY spectrum $(500 \mathrm{MHz})$ of synthetic acinetobactin TFA salt in DMSO-d6. Correlations are listed in Table S3. 


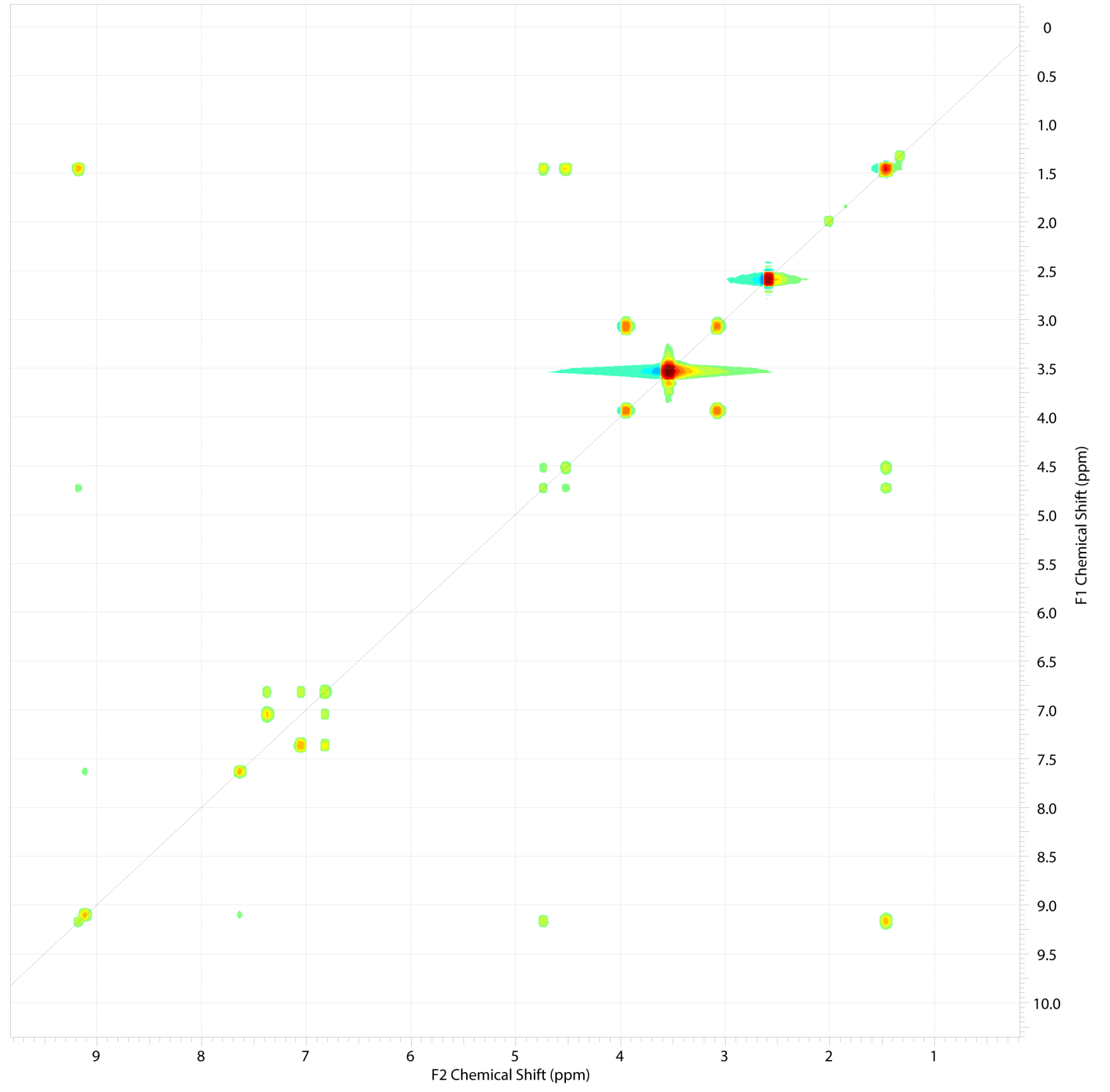

Figure S31. TOCSY spectrum $(500 \mathrm{MHz})$ of synthetic acinetobactin TFA salt in DMSO-d6. Correlations are listed in Table S3. 


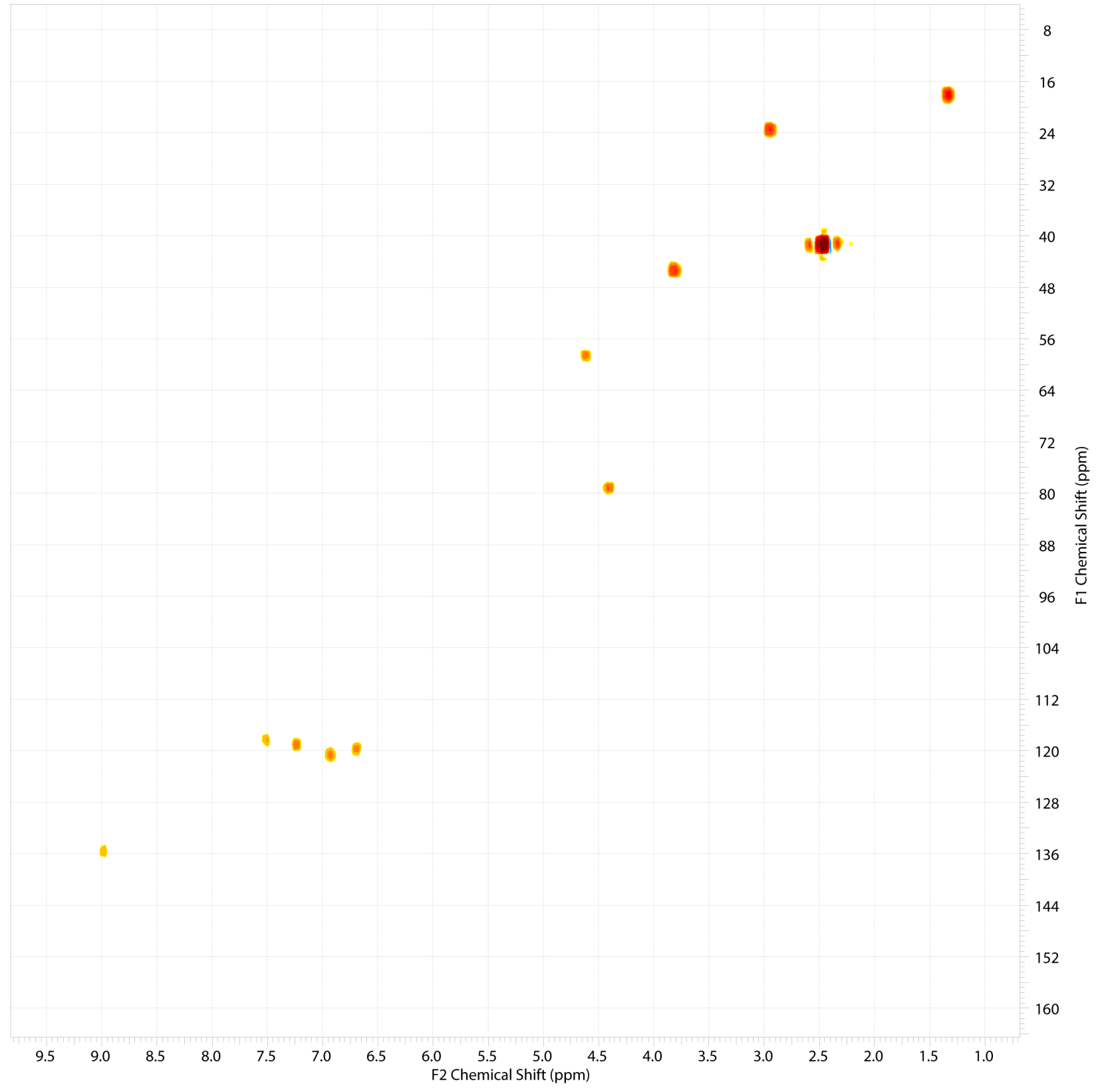

Figure S32. gHSQC spectrum $(500 \mathrm{MHz})$ of synthetic acinetobactin TFA salt in DMSO-d6. Correlations are listed in Table S3. 


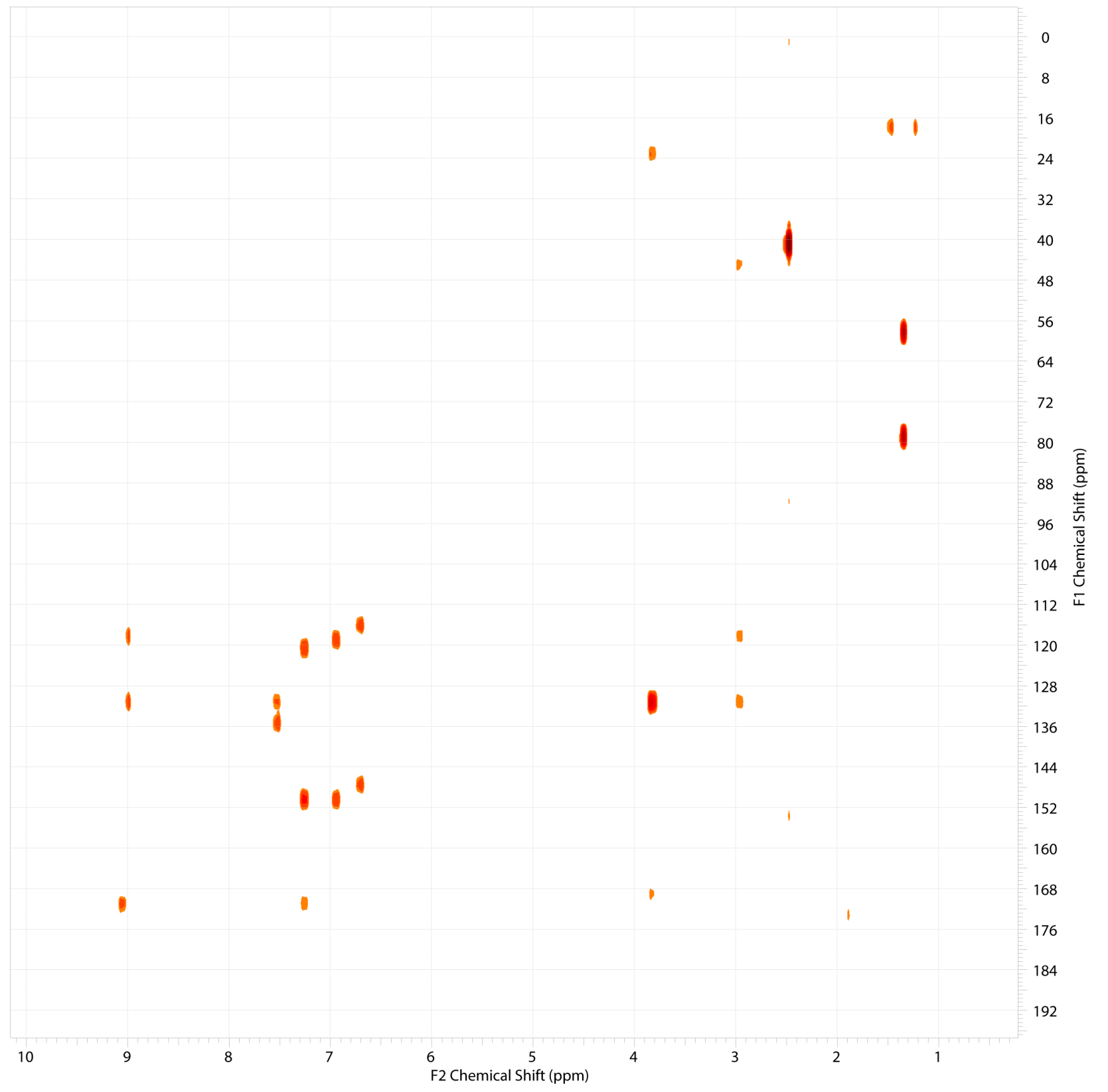

Figure S33. HMBC spectrum $(500 \mathrm{MHz})$ of synthetic acinetobactin TFA salt in DMSO-d6. Correlations are listed in Table S3. 


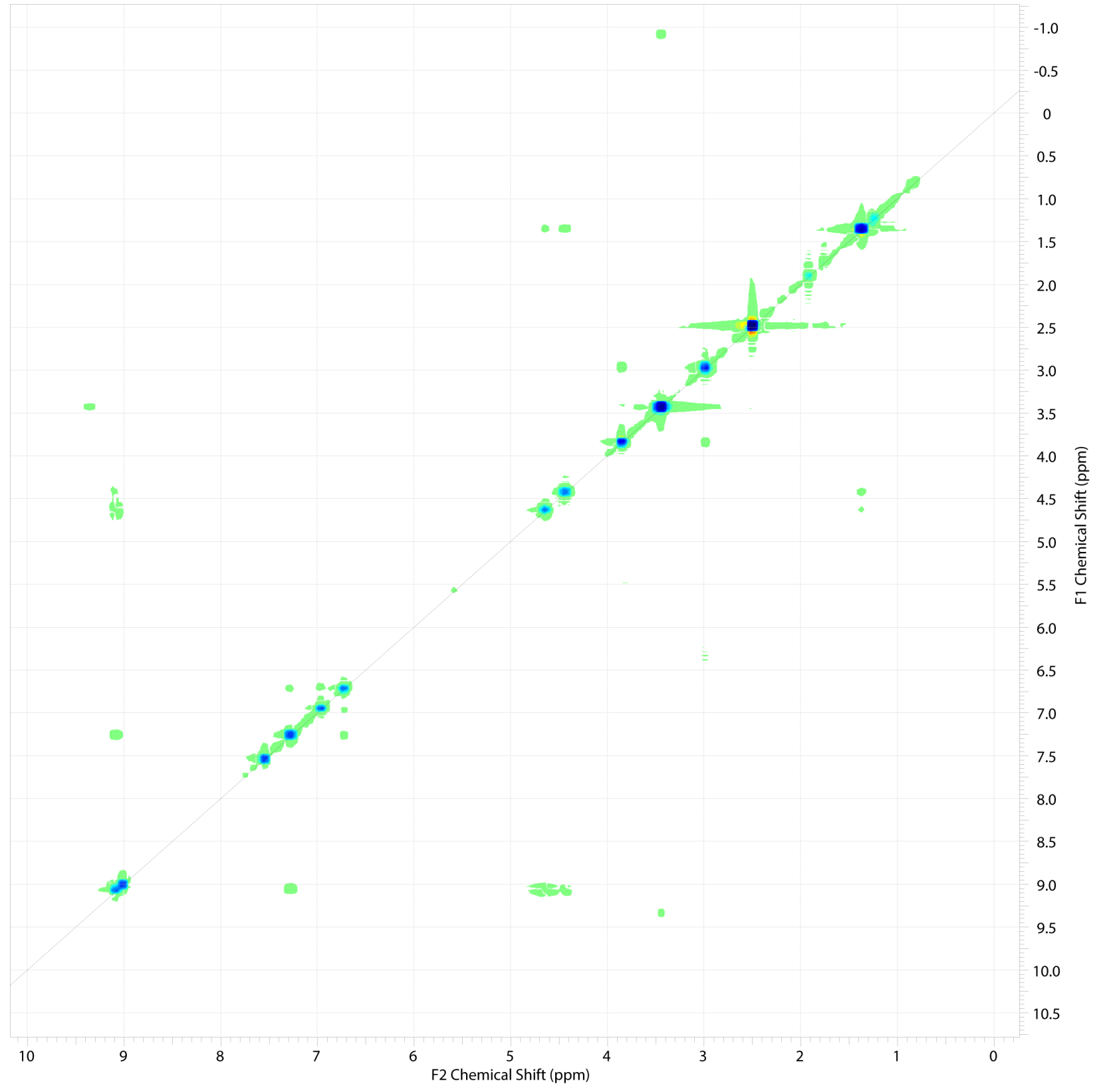

Figure S34. ROESY spectrum $(500 \mathrm{MHz})$ of synthetic acinetobactin TFA salt in DMSO-d6. Correlations are listed in Table S3. 


\section{A. baumannii Growth Curves}

pH 5.7200 uM DIP
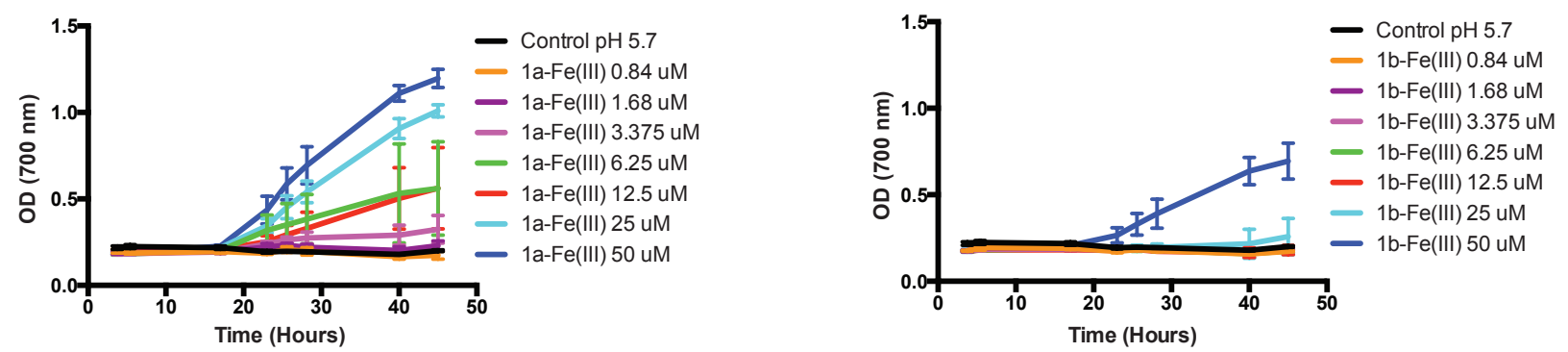

pH 6.5250 uM DIP
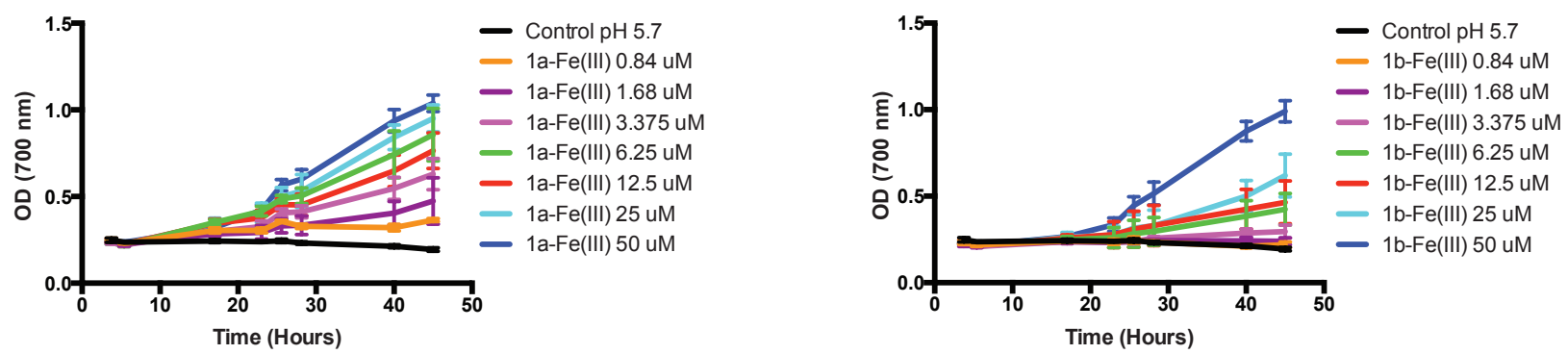

pH 7.5 250 uM DIP
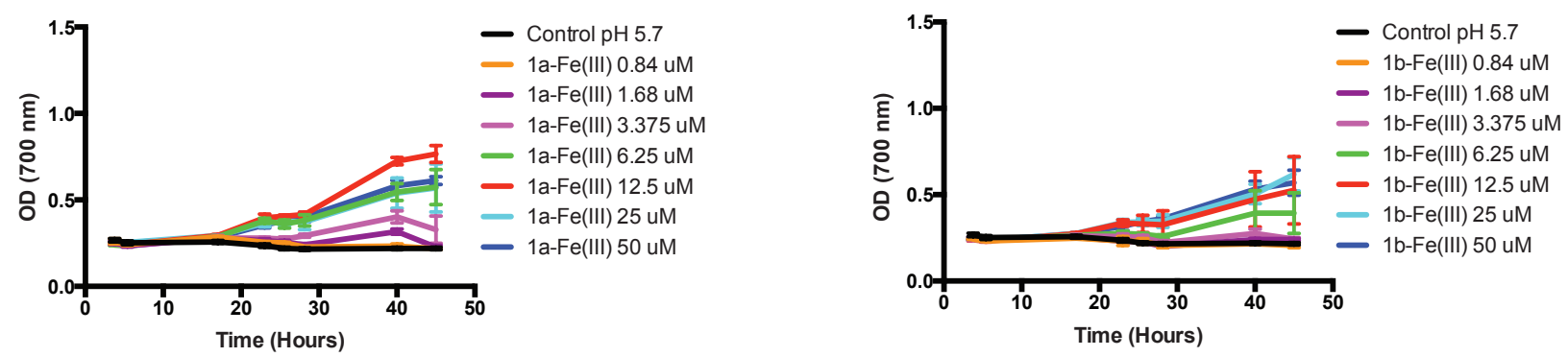

Figure S35. Growth promotion of A. baumannii ATCC 17978 in iron deficient M9 minimal media at $37{ }^{\circ} \mathrm{C}$. (A) M9 minimal media, $\mathrm{pH}$ 5.7, $200 \mu \mathrm{M}$ DIP, serial dilution of preacinetobactinFe(III), (B) M9 minimal media, pH 5.7, $200 \mu \mathrm{M}$ DIP, serial dilution of acinetobactin-Fe(III), (C) M9 minimal media, $\mathrm{pH} 6.5,250 \mu \mathrm{M}$ DIP, serial dilution of preacinetobactin-Fe(III), (D) M9 minimal media, pH 6.5, $250 \mu \mathrm{M}$ DIP, serial dilution of acinetobactin-Fe(III), (E) M9 minimal media, $\mathrm{pH} 7.5,250 \mu \mathrm{M}$ DIP, serial dilution of preacinetobactin-Fe(III), (F) M9 minimal media, $\mathrm{pH}$ 7.5, $250 \mu \mathrm{M}$ DIP, serial dilution of acinetobactin-Fe(III). 
19606 1a-Fe(III)

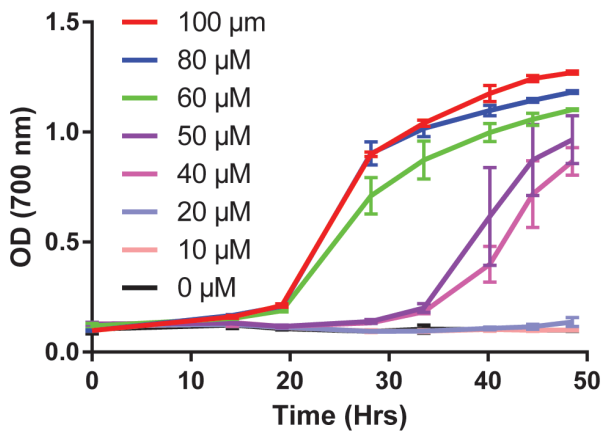

19606 t6 1a-Fe(III)

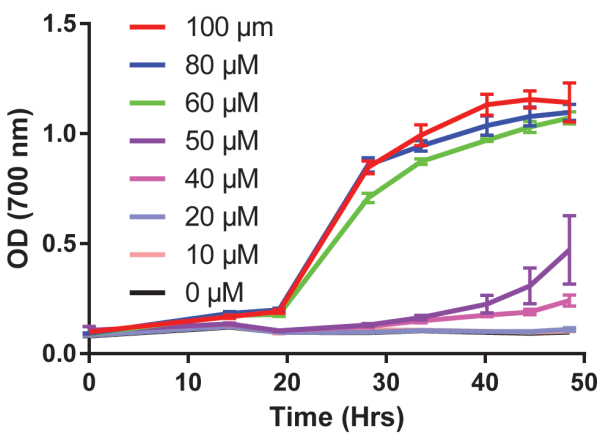

19606 t7 1a-Fe(III)

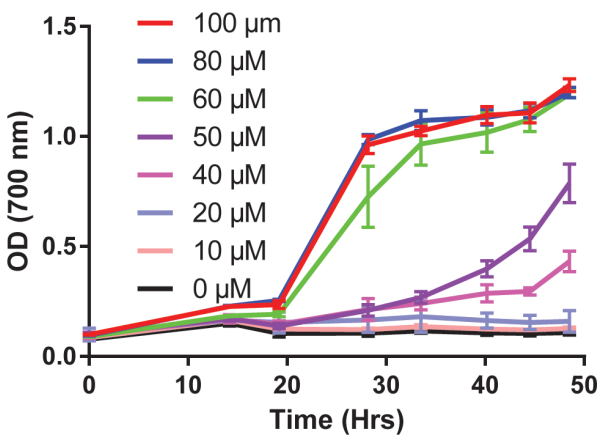

19606 s1 1a-Fe(III)

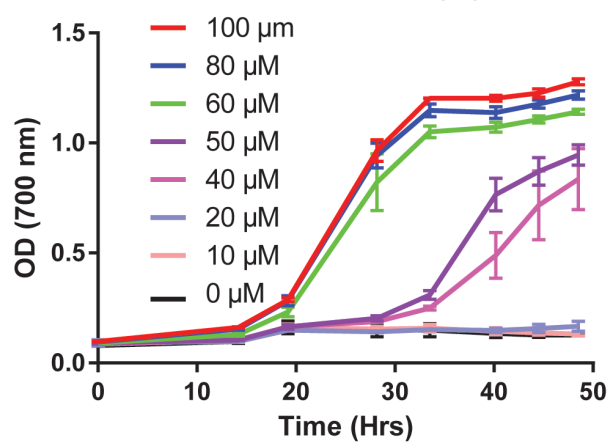

19606 1b-Fe(III)

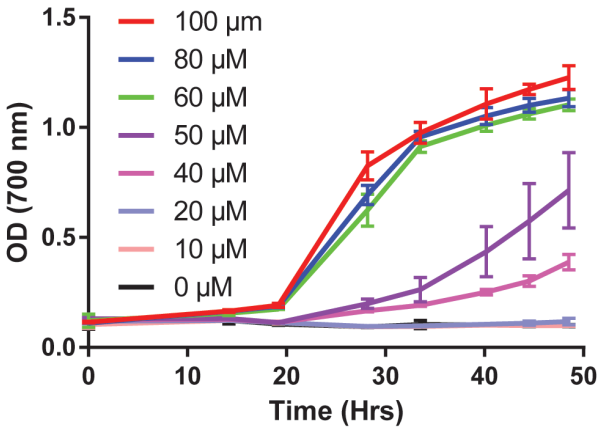

19606 t6 1b-Fe(III)

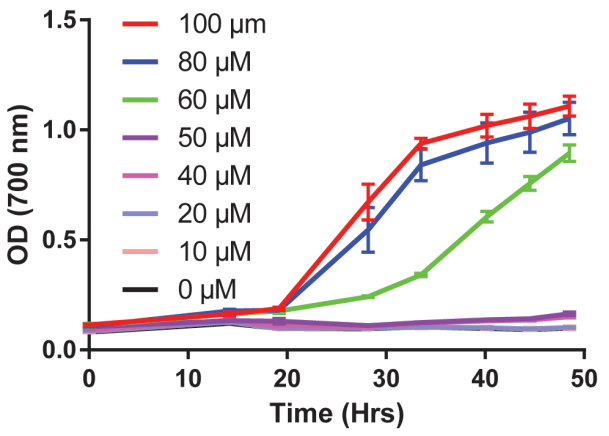

19606 t7 1b-Fe(III)

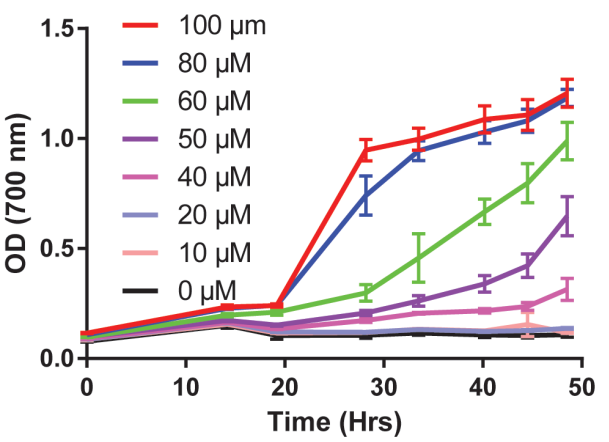

19606 s1 1b-Fe(III)

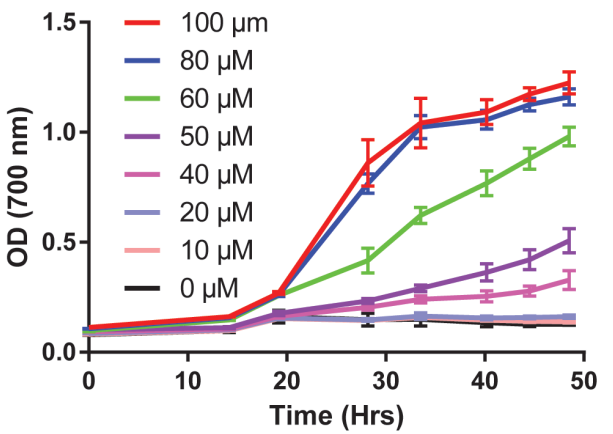

Figure S36. Growth promotion of A. baumannii ATCC 19606 and mutant strains ${ }^{14}$ in iron deficient M9 minimal media at $37{ }^{\circ} \mathrm{C}$. All experiments were performed in $\mathrm{M} 9$ minimal media $\mathrm{pH}$ $6.5+250 \mu \mathrm{M}$ DIP, gradient concentration of pre-acinetobactin-Fe(III) and acinetobactin-Fe(III). 


\section{Acknowledgments}

We thank Dr. Andre D'Avignon (formerly WUSTL, Dept. of Chemistry; currently Sanford Burnham Medical Research Institute, Orlando, FL), Dr. Jeff Kao (WUSTL, Dept. of Chemistry), and Dr. Brian Marsden (WUSTL, Dept. of Chemistry) for assistance provided in the acquisition and processing of 2D NMR spectra. We thank Prof. Carl Frieden and Dr. Qin Shu in the Department of Biochemistry and Molecular Biophysics at Washington University in St. Louis School of Medicine for assistance with CD measurements. We thank Dr. Sophie Alvarez at the Washington University Danforth Plant Science Center for assistance with the acquisition of highresolution MS-MS spectra. A special thanks to Dr. Luis Actis (Miami University, Dept. of Microbiology) for providing A. baumannii ATCC 19606 t6, t7, and s1 mutants.

\section{References}

(1) Mihara, K.; Tanabe, T.; Yamakawa, Y.; Funahashi, T.; Nakao, H.; Narimatsu, S.; Yamamoto, S. Microbiology (Reading, U.K.) 2004, 150, 2587.

(2) Sattely, E. S.; Walsh, C. T. J. Am. Chem. Soc. 2008, 130, 12282.

(3) Wuest, W. M.; Sattely, E. S.; Walsh, C. T. J. Am. Chem. Soc. 2009, 131, 5056.

(4) Mortensen, B. L.; Skaar, E. P. Front. Cell Infect. Microbiol. 2013, 3, 95.

(5) Takeuchi, Y.; Ozaki, S.; Satoh, M.; Mimura, K.; Hara, S.; Abe, H.; Nishioka, H.; Harayama, T. Chem. Pharm. Bull. 2010, 58, 1552.

(6) Hossain, M. B.; Jalal, M. F.; van der Helm, D. J. Chem. Crystallogr. 1998, $28,57$.

(7) Pople, J. A.; Scott, A. P.; Wong, M. W.; Radom, L. Isr. J. Chem. 1993, 33, 345.

(8) Cossi, M.; Rega, N.; Scalmani, G.; Barone, V. J. Comput. Chem. 2003, 24, 669.

(9) Shephard, M. J.; Paddon-Row, M. N. J. Phys. Chem. 1995, 99, 3101.

(10) Zhao, Y.; Truhlar, D. G. Acc. Chem. Res. 2008, 41, 157.

(11) Rydberg, P.; Olsen, L. J. Phys. Chem. A 2009, 113, 11949.

(12) Ansbacher, T.; Srivastava, H. K.; Martin, J. M.; Shurki, A. J. Comput. Chem. 2010, 31, 75 .

(13) Weigend, F.; Ahlrichs, R. Phys. Chem. Chem. Phys. 2005, 7, 3297.

(14) Dorsey, C. W.; Tomaras, A. P.; Connerly, P. L.; Tolmasky, M. E.; Crosa, J. H.; Actis, L. A. Microbiology 2004, 150, 3657. 